\title{
DOE/OR/00033-.T 765
}

Development of a Kinetic Model and Calculation of Radiation Dose Estimates for Sodium Iodide-131I in Athyroid Individuals

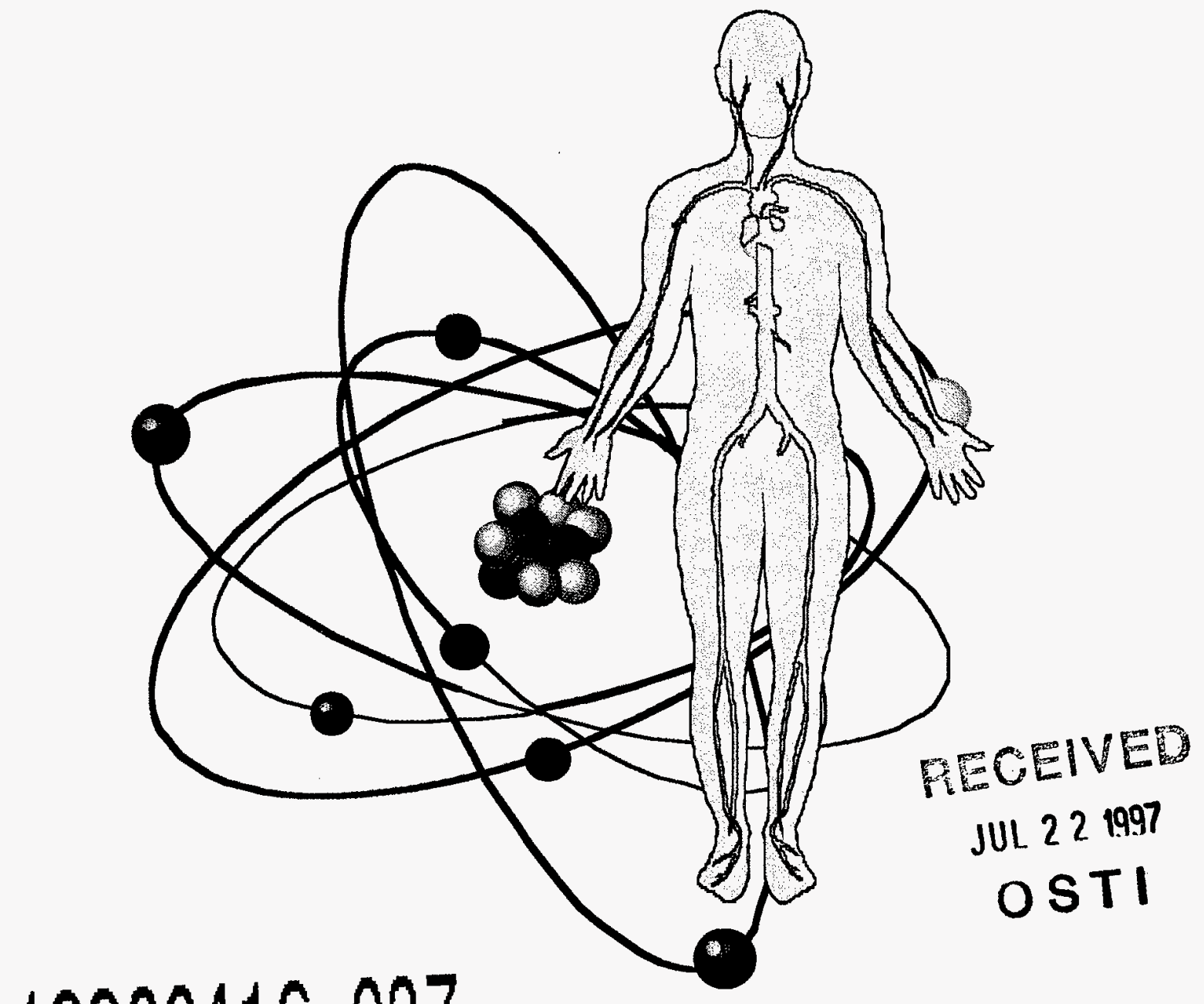

19980416037

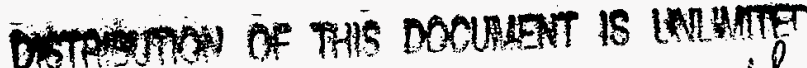

By:

Michalene Rodriguez

Master's Project

Colorado State University

Fort Collins, Colorado

This research was performed under appointment to the Applied Health Physics

Fellowship Program administered by Oak Ridge Institute for Science and Education

for the U. S. Department of Energy 


\section{DISCLAIMER}

This report was prepared as an account of work. sponsored by an agency of the United States Government. Neither the United States Government nor any agency thereof, nor any of their employees, makes any warranty, express or implied, or assumes any legal liability or responsibility for the accuracy, completeness, or usefulness of any information, apparatus, product, or process disclosed, or represents that its use would not infringe privately, owned rights. Reference herein to any specific commercial product, process, or service by trade name, trademark, manufacturer, or otherwise does not necessarily constitute or imply its endorsement, recommendation, or favoring by the United States Government or any agency thereof. The views and opinions of authors expressed herein do not necessarily state or reflect those of the United States Government or any agency thereof. 


\section{Acknowledgements}

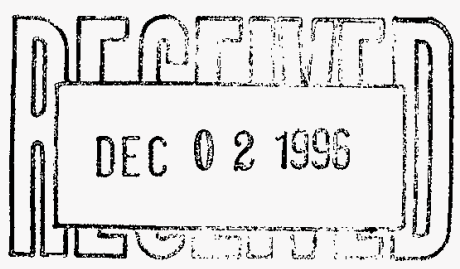

This research was performed under appointment to the Applied Health Physics Fellowship Program administered by Oak Ridge Institute for Science and Education for the U. S. Department of Energy. I would like to acknowledge and thank the Fellowship Program Manager, Mr. Thomas R. Richmond, and assistant Rose Etta Cox, for giving me the opportunity to successfully complete my education. I wish the Fellowship Program and all individuals involved a continuous and successful future.

My research was performed at the Radiation Internal Dose Information Center, Oak Ridge, Tennessee. I would specifically like to thank Michael G. Stabin and Richard Sparks in providing a great deal of assistance towards my project. I appreciate their patience over the last year and value the friendship we have developed.

I would like to recognize Liz Brackett, Pete Hollenbeck, and Wilhelmina Buijs, for their contribution of specific data. I appreciate your interests regarding the subject matter.

I would like to thank my advisor, Dr. Thomas Borak, for all the support and guidance he has provided to me over the last three years, and also special thanks to my committee members, Dr. Patricia Vigil and Dr. David Rowan. Their input and advice regarding this project has been extremely valuable.

Finally, I would like to express my deepest gratitude to my family. Their unending support and strength has meant a great deal to me. Also, a very special thank you to my mother for making me realize the importance of an education and for showing me the right paths to take. 


\begin{abstract}
The treatment for some thyroid carcinomas involves surgically removing the thyroid gland and administering the radiopharmaceutical Sodium iodide - ${ }^{131} \mathrm{I}(\mathrm{NaI})$. A diagnostic dose of $\mathrm{NaI}$ is given to the patient to determine if remnant tissue from the gland remains or larger doses are administered in order to treat the malignant tissue.

Past research regarding $\mathrm{NaI}$ uptake and retention in euthyroid individuals (normal functioning thyroid) reveal that radioiodine concentrates mainly in the thyroid tissue and the remaining material is excreted from the body. The majority of radioiodine in athyroid (without thyroid) individuals is also eliminated from the body; however, there has been recent evidence of a long-term retention phase for individuals with no radioiodine concentrating tissue. Thus, the long-term component indicates the binding of radioiodine to other tissues in the body.
\end{abstract}

The general purpose of this study was to develop a kinetic model and estimate the absorbed dose to athyroid individuals regarding the distribution and retention of $\mathrm{NaI}$.

The iodine kinetics in three athyroid individuals was fitted to a 4-compartment model. The residence times were calculated using multi-exponential curve fitting techniques with a mean of 13.5 hours and a mean biological half-life of 5 days. The dose estimates to 26 target organs were determined for the short and long-term retention phases. 
Uncertainty estimates were done by propagating the uncertainty through the residence time. The uncertainty involved in the residence time was most likely due to inter-patient variability. The mean residence time was 13.5 hours with a standard deviation of 1.3 hours. Assuming the residence time is normally distributed, then the $95 \%$ confidence interval was between 10.9 and 16.1 hours.

It was concluded the long-term retention component contributed less than 5 percent to the total dose for the three individuals. However, to validate the results, a larger sample size would be required, thus further analysis and research would be needed. 


\section{CONTENTS}

CHAPTER

PAGE

I. Introduction 1

II. Thyroid Anatomy and Physiology 4

A. Thyroid Anatomy 4

B. Iodine Metabolism: Synthesis and Secretion of Thyroid Hormones 6

1. Thyroid Hormones 6

2. Synthesis of Thyroid Hormones 7

3. Secretion of Thyroid Hormones 9

4. Transport of Thyroid Hormones 10

C. Extrathyroidal Iodide Transport 10

1. Salivary Glands 11

2. Stomach and Intestines $\quad 11$

3. Mammary Gland 12

4. Hair and Skin 12

III. Kinetic Models and Calculation of Estimated Absorbed Doses 13

$\begin{array}{ll}\text { A. Compartmental Models } & 13\end{array}$

B. Mathematical Models 16

1. Substitution Method 18

2. Matrix Method 19

3. Laplace Transformation Method 19

C. Absorbed Dose 25

1. Distribution and Retention of the Radiopharmaceutical 29

2. Physical Properties of the Radionuclide 33

$\begin{array}{ll}\text { IV. Model Analyses } & 38\end{array}$
A. Verification Analysis $\quad 39$
B. Validation Analysis $\quad 39$ 
C. Sensitivity Analysis 41

D. Uncertainty Analysis 42

E. Simulation Analysis and Modeling (SAAM) 43

1. ICRP Publication 30 Gastrointestinal and Lung Models 44

V. Iodine Kinetics and Absorbed Dose Estimates for Athyroidic Individuals 50

A. Physical Data $\quad 51$

B. Patient Data $\quad 52$

C. Athyroid Model 56

D. Estimated Absorbed Dose 65

1. MIRDOSE 65

E. Uncertainty Analysis $\quad 67$

$\begin{array}{ll}\text { VI. Conclusions } & 73\end{array}$

$\begin{array}{ll}\text { REFERENCES } & 75\end{array}$

$\begin{array}{ll}\text { APPENDIX A } & 78\end{array}$

$\begin{array}{ll}\text { APPENDIX B } & 81\end{array}$ 


\section{LIST OF TABLES}

TABLE

PAGE

4-1 Initial conditions and transfer rate coefficients for standard GI tract model for ${ }^{123}$ I sodium iodide.

4-2 Predicted/Actual ratio over time for the stomach and lower large intestine compartments for the standard GI model using ${ }^{123}$ I sodium iodide as the tracer.

4-3 Predicted/Actual ratio over time for compartment $d$ of the lung model using ${ }^{123} I$ sodium iodide as the tracer.

5-1 Physical characteristics of ${ }^{131} \mathrm{I}$.

5-2 Urinary excretion data for patient 1 . Therapeutic dose of $100 \mathrm{mCi}$ delivered on $1 / 17 / 90$.

5-3 Urinary excretion data for patient 2. Therapeutic dose of $150 \mathrm{mCi}$ delivered on $1 / 17 / 90$.

5-4 Urinary excretion data for patient 3. Diagnostic dose of $4 \mathrm{mCi}$ delivered on $1 / 14 / 91$.

5-5 Estimated transfer rate coefficients predicted by SAAM.

5-6 Residence times generated by SAAM.

5-7 Percent difference in residence times predicted by SAAM versus the observed values from the analytical solution.

5-8 Percent of activity in urine at 24 and 48 hours.

5-9 Percent of whole-body radioiodine retention for athyroid patients.

5-10 Estimated absorbed dose for the short and long components.

5-11 Mean, standard deviation, and partial derivative of $\tau$ with respect to the various parameters. 


\section{LIST OF FIGURES}

FIGURE

PAGE

2-1 Gross anatomy of the thyroid gland.

2-2 Microscopic view of the thyroid follicles.

6

2-3 Synthesis and secretion of thyroid hormones $\mathrm{T}_{3}$ and $\mathrm{T}_{4}$.

2-4a The combination of one DIT molecule and one MIT molecule produces $T_{3}$.

2-4b The binding of two MIT molecules produces $\mathrm{T}_{4}$.

9

3-1a Sample mammillary model for biokinetic analysis.

15

3-1b Sample catenary model for biokinetic analysis.

3-2 A two-compartmental model with designated transfer rate coefficients.

3-3 Designated source and target regions for three radiopharmaceuticals used in nuclear medicine procedures.

3-4 Distribution sites for ${ }^{99 \mathrm{~m}} \mathrm{Tc}$ when labeled to different compounds.

3-5 Illustration of residence time with the area under the time-activity curve representing the accumulated activity which is equal to the area of the rectangle.

3-6 Time-activity curve representing instantaneous uptake by the source organ.

3-7 The concept of absorbed fraction, $\phi$, as demonstrated for penetrating and non-penetrating radiations.

4-1 ICRP 30 GI tract kinetic model.

4-2 ICRP 30 lung model. 
4-3 Activity as a function of time based on the analytical solution and SAAM 31 results for stomach compartment.

4-4 Activity as a function of time based on the analytical solution and SAAM 31 results for lower large intestine.

4-5 Activity as a function of time based on the analytical solution and SAAM 31 results for compartment $d$ of the lung model.

5-1 Basic model describing the kinetics of iodine. Transfer rate coefficients are given in units of day ${ }^{-1}$.

5-2 Compartmental model describing the kinetics of NaI for athyroid adult individuals.

5-3 Patient 1, percent of administered activity as a function of time based on curve fitting results using the SAAM software.

5-4 Patient 2, percent of administered activity as a function of time 


\section{Chapter I}

Introduction

Nuclear medicine was established in the 1930s and has since become an important tool used by the medical community. Nuclear medicine involves the use of radioactive tracers administered to the patient by means of intravenous injection, inhalation, or ingestion in order to diagnose and treat disease. Information regarding the structure, function, secretion, excretion, and volume of a particular organ(s) can be obtained by detecting the radiation emitted from a tracer which is taken up by the organ(s) (Gurley and Callaway 1992).

Diagnostic nuclear medicine procedures can be beneficial to patients by discovering or measuring the extent of disease. Therapeutic procedures involve the administration of larger amounts of radioactive material to the patient in order to treat a specific disease. The goal in either case is to maximize the desired effect while minimizing the associated risk of undesirable outcomes (NCRP 1982). The risk to the patient can be estimated once the absorbed dose to various internal organs or tissues from the radiopharmaceutical in question is known. Currently there are several methods used to estimate the absorbed dose to organ systems. The most common method in use today was developed by Loevinger and Berman (1976) and adopted by the Medical Internal Radiation Dose (MIRD) Committee of the Society of Nuclear Medicine.

To estimate absorbed doses in the MIRD technique, required information is needed pertaining to the biological distribution and retention of the radiopharmaceutical and the physical 
properties of the radionuclide. Detailed information is available concerning the physical properties of many commonly used radionuclides and can be found in the published literature. However, the biological data on the distribution and retention for some radiopharmaceuticals is not well known or understood. Compartmental models are used to aid in understanding the distribution, metabolism, and behavior of a biological system. Compartmental models give a simplified visual description of a system, with transfer rate coefficients describing the fraction of the tracer entering or leaving other compartments. Mathematical models are used to give quantitative information about the system and are used to describe the time dependent behavior of the radioactive substance within the region(s) of interest. Although a great deal of information and knowledge can be obtained from models, there are assumptions made in constructing the model and limitations within the results that must be considered. Methods such as validation, sensitivity, and uncertainty analyzes, or comparable techniques, should be conducted to evaluate the model's capabilities.

Sodium iodide- ${ }^{131} \mathrm{I}(\mathrm{NaI})$ was one of the first radiopharmaceuticals used in nuclear medicine to diagnose and treat thyroid disease. The metabolism, distribution, retention, and physical properties of radioiodine have since been established by Berman et al. (1968). Compartmental and mathematical models describing the behavior of radioiodine in the human body range from simple to complex. MIRD Dose Estimate Report No. 5 (Berman et al. 1975) describes in detail the kinetics of ${ }^{131} \mathrm{I}$ and lists the estimated absorbed doses to several regions of interest. Recently, however, a long term retention component has been observed in persons whose thyroids had been previously removed through surgery or radioiodine therapy (Brackett, Eckerman, and Hollenbeck; unpublished data). This component is not accounted for in the MIRD Dose Estimate Report 
Model, and thus the radiation dose which might result from this component has not been estimated.

The purpose of this paper is to review current knowledge, and describe the development of a kinetic model and radiation dosimetry for this additional long term component. 


\section{Chapter II}

Thyroid Anatomy and Physiology

\section{A. Thyroid Anatomy}

The thyroid gland is one of the major organs belonging to the endocrine system and is unique in many ways. It is one of the largest endocrine glands in the body, weighing approximately 20 grams in normal adults; it is highly vascular; and it is capable of storing large amounts of thyroid hormones (Williams 1968).

The thyroid gland consists of two main lobes connected by a thin layer of tissue called the isthmus. The gland is attached to the anterior and lateral surface of the trachea and is held by loose connective tissue (Figure 2-1). Two pairs of parathyroid glands are located on the posterior surface of the thyroid lobes. The thyroid is highly vascularized with a blood flow ranging from 0.07 to $0.10 \mathrm{ml} \mathrm{s}^{-1} \mathrm{~g}^{-1}$. The thyroid receives its blood supply from the superior thyroid artery, arising from the common carotid artery and the inferior thyroid artery from the subclavian arteries (Seeley et al. 1995).

At the microscopic level, the thyroid gland is composed of numerous follicles or acini (Figure 2-2). The follicles are small sacs filled with proteinaceous colloids consisting of thyroglobulin molecules to which iodine atoms are bound. The follicles constitute the majority of the total thyroid mass. They vary in size with an average diameter of $200 \mu \mathrm{m}$. The supply of iodine stored by a follicle varies with the surface area of the individual follicle (Williams 1968). 
Attached to the basement membrane of each follicle is a wall of closely packed cuboidal epithelial cells which is the production site of the glycoprotein thyroglobulin (Marieb 1992). The epithelial cells also vary in size, becoming columnar when stimulated and flat when inactive (Williams 1968).

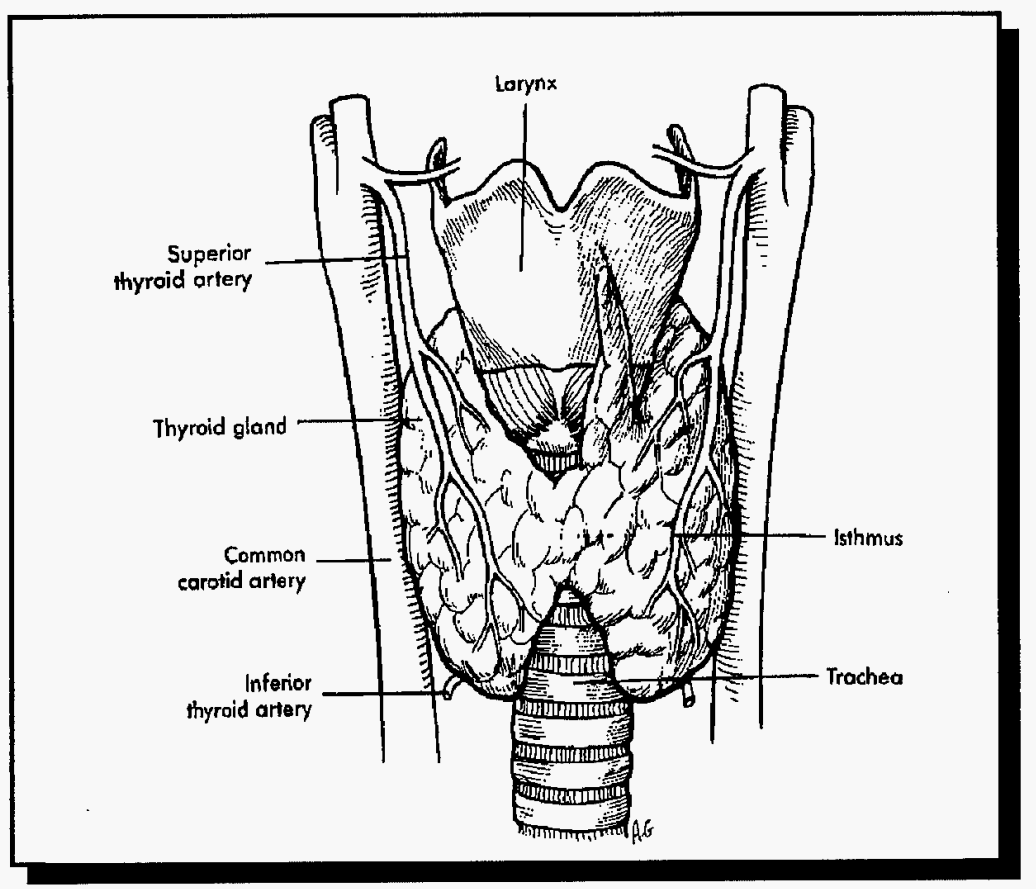

Figure 2-1. Gross anatomy of the thyroid gland (Seeley et al. 1995). 


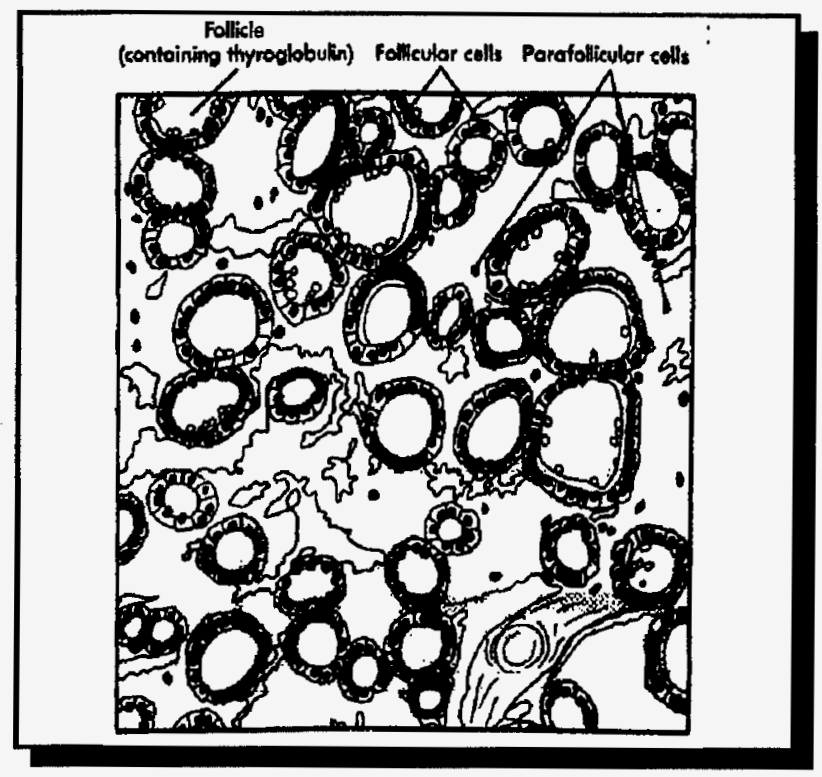

Figure 2-2. Microscopic view of the thyroid follicles (Seeley et al. 1995).

\section{B. Iodine Metabolism: Synthesis and Secretion of Thyroid Hormones}

\section{Thyroid Hormones}

The two hormones which are synthesized within the thyroid gland are triiodothyronine $\left(\mathrm{T}_{3}\right)$ and tetraiodothyronine $\left(\mathrm{T}_{4}\right)$, also known as thyroxine. Thyroxine is the major hormone produced within the thyroid (90\%), and $T_{3}$ is mostly formed at the target tissues by conversion of $T_{4}$ to $T_{3}$ (Marieb 1992).

The thyroid hormones are very important in that they effect virtually every tissue in the body, except for the adult brain, spleen, testes, uterus, and thyroid gland (Marieb 1992). Thyroid 
hormones play an important role in maintaining normal levels of body temperature, blood pressure, and regulate the growth and development of many organs (Seeley et al. 1995).

\section{Synthesis of Thyroid Hormones}

The normal pathway for inorganic iodine, in the form of an iodide ( $\left.\mathrm{I}^{-}\right)$, is through dietary intake. Inorganic iodine can enter the body through food and water consumption, and sometimes through medication and food supplements (Williams 1968). Iodine intake can vary significantly in different individuals. In highly developed countries, such as the United States, an average dietary iodine intake is approximately $200 \mu \mathrm{g}$ daily, whereas in Japan, where the majority of the foods are rich in iodine, intake can be as much as 2-3 milligrams day ${ }^{-1}$ (Williams 1968). In underdeveloped countries the iodine intake can be much lower, although generally no increase in thyroid disease is observed (Williams 1968).

Once inorganic iodine is taken into the body, it is distributed throughout the body via the extracellular fluids. The majority of iodine is removed from the bloodstream by two pathways, the thyroid and the kidneys. In the normal adult, approximately 75 percent of iodine ingested daily is filtered by the kidneys and excreted into the urine (Williams 1968). Renal removal of iodine from the body determines how much iodine is available to the thyroid for the production of thyroid hormones. There are several processes which direct thyroid hormone synthesis, all of which are interdependent (Figure 2-3). The first process of interest is the secretion of Thyroid Stimulating Hormone (TSH). TSH is released from the adenohypophysis of the anterior pituitary gland and binds to the membrane-bound receptors located on the thyroid follicular cells. TSH is regulated 
by thyrotropin-releasing hormone from the hypothalamus and is managed by a negative feedback mechanism (Seeley et al. 1995). Thyroglobulin proteins, which contain many amino acid tyrosines, are synthesized within the follicle cells by the stimulation of TSH (Seeley et al. 1995). Iodide ions are actively transported into the cells from the extracellular fluids and are oxidized to form iodine. Iodine binds to the tyrosine amino acids of the thyroglobulin molecules at approximately the same time thyroglobulin enters the follicle's lumen. Two iodine atoms bound to a tyrosine molecule constitutes diiodotyrosine (DIT), and one iodine atom bound to one tyrosine molecule produces monoiodotyrosine (MIT). $\mathrm{T}_{4}$ is produced by the joining of two DIT molecules, and $\mathrm{T}_{3}$ production is caused by bonding of MIT and DIT molecules (Figures 2-4a and 2-4b) (Marieb 1992).

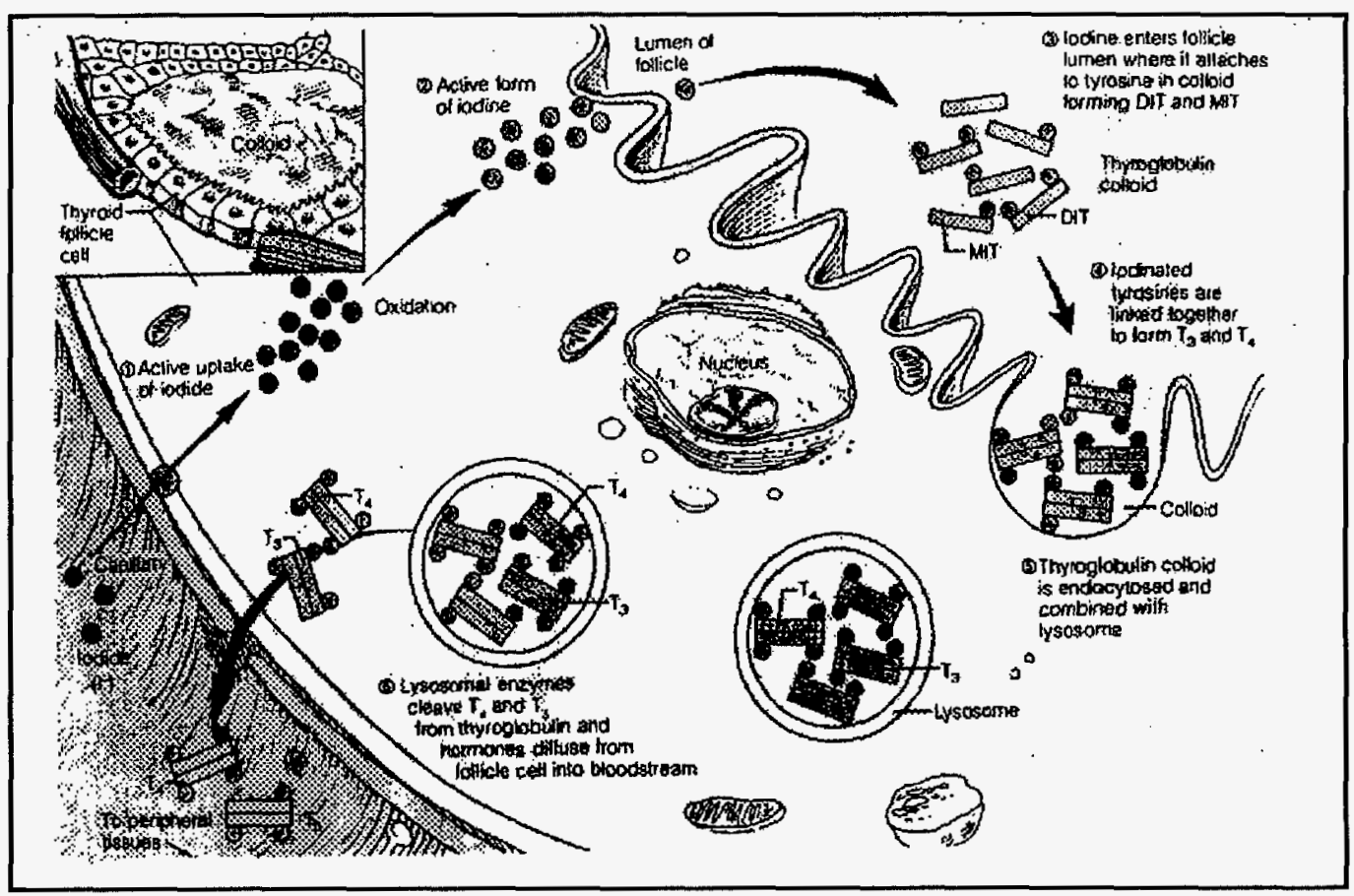

Figure 2-3. Synthesis and secretion of thyroid hormones $T_{3}$ and $T_{4}$ (Marieb 1992). 


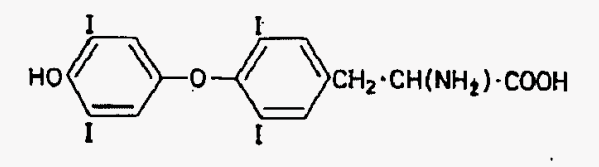

$(2-4 a)$

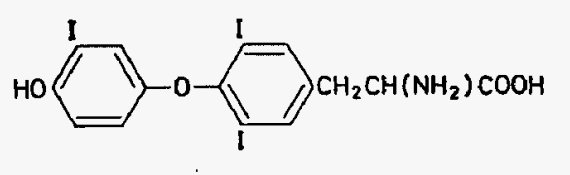

$(2-4 b)$

Figure 2-4. (2-4a) The binding of two MIT molecules produces $T_{4}$.

(2-4b) The combination of one DIT molecule and one MIT molecule produces $\mathrm{T}_{3}$.

At this point, $T_{3}$ and $T_{4}$ hormones are still linked to the thyroglobulin molecules, and large amounts of each are stored in the lumen of the follicle. The storage of the thyroid hormones remains relatively constant, and if needed, can provide the sufficient levels required by its target tissues for 2 to 3 weeks (Marieb 1992).

\section{Secretion of Thyroid Hormones}

By the time that endocytosis has occurred, iodinated thyroglobulin has migrated from the lumen to the follicle cell where it connects with lysosomes (Figure 2-3). Proteolytic enzymes are released within the cell and sever the peptide bonds between $T_{3}, T_{4}$ and thyroglobulin. The thyroid hormones then diffuse from the cells and bind predominately to plasma proteins in the bloodstream. The deiodinated tyrosines are used to synthesize more thyroglobulin (Marieb 1992). 


\section{Transport of Thyroid Hormones}

Approximately 75 percent of the released hormones bind to the plasma protein, thyroxinebinding globulin, which is produced by the liver. The two circulating hormones are transported to their target tissues by binding to the appropriate receptors. Of the two circulating hormones, $\mathrm{T}_{3}$ is transported to its target tissues and binds to the appropriate receptors much more rapidly than $\mathrm{T}_{4}$. Approximately $35-40$ percent of $\mathrm{T}_{4}$ is converted to $\mathrm{T}_{3}$ by the appropriate body tissues, the remaining $T_{4}$ is excreted in the urine or bile as $T_{4}$ or abnormal $T_{3}$ (Seeley et al. 1995).

\section{Extrathyroidal Iodide Transport}

The above process describes the transport of iodide into and out of the thyroid gland; however, iodide transport is not restricted to the thyroid. A small amount of inorganic iodide from the extracellular fluid can concentrate in other organs within the body. Unlike the thyroid, these specific organs do not have the capability of synthesizing and secreting $T_{3}$ and $T_{4}$ hormones, but eventually the iodide is reabsorbed back into the extracellular space and is excreted from the body or taken up by the thyroid gland (Pitt-River and Trotter 1964). The importance of iodide transport into certain organs other than the thyroid is unknown, however, it may prolong the retention of iodide in the body.

In a paper by Brown-Grant (1961), mechanisms of iodide accumulation in several different organs are discussed. Although his results are based mostly on animal data, certain functional 
characteristics of specific tissues are probably also represented in humans. The remainder of this chapter briefly discusses the iodide concentration in several organs other than the thyroid, as this subject will play an important role in the remainder of this paper.

\section{Salivary Glands}

Based on ${ }^{131} \mathrm{I}$ used as a tracer on human subjects, an iodide concentration appears in the secretory products of the salivary glands, mainly the saliva. The ${ }^{131} \mathrm{I}$ appears at a higher concentration than in the plasma (30 to 40 times higher) and is present as inorganic iodide. Radioiodine is detected in the saliva within seconds after injection. Also revealed in this study is the fact that salivary clearance of iodide is independent of the rate of secretion of saliva. It is proposed that the duct cells of the gland may act as a reservoir for iodide (Brown-Grant 1961).

\section{Stomach and Intestines}

Animal and human studies using ${ }^{131} \mathrm{I}$-labeled thiocyanate reveal an iodide concentration in the stomach wall and gastric juice. Human studies show a very slow absorption rate from the stomach, with the secretion of iodide by the gastric mucosa. An ${ }^{131}$ I stomach juice/plasma ratio of up to 40 is observed in many cases. This suggests there may be a relationship between the volume of juice secreted and the concentration ratio (Brown-Grant 1961). From the gastrointestinal tract, the small intestine rapidly absorbs iodide; however, there is no evidence of iodide in the duodenal juice of man (Brown-Grant 1961). 


\section{Mammary Gland}

It is well known that the fetal thyroid begins to concentrate iodine at about 90 days after conception (Watson 1992). The fetal thyroid receives its supply of iodide from the mother and it is believed the secretions of the mammary gland takes over this function after birth (Brown-Grant 1961).

Studies using administered ${ }^{131} \mathrm{I}$ in human and animal subjects reveal radioiodine concentrations in the milk approximately to be 20 to 30 times the plasma level. Unlike the salivary glands, stomach, and intestine, there is evidence that part of the iodine is present in an organic form, but that this form appears to exist only after the milk has been secreted by the alveolar cells (Brown-Grant 1961).

\section{Hair and Skin}

Iodide concentration in skin and hair is observed in albino rats, but not in other species studied (Brown-Grant 1961). It should be noted that in the animals one to ten days old, approximately 30 percent of the administered iodide is found in the skin up to 5 days post injection, a concentration higher than that in the thyroid. In adult rats, 24 hours after injection, 3 to 5 percent of radioiodine is present in the skin and remains there for approximately 10 days. Iodide uptake in the hair is also detected with a high iodide content, second only to the thyroid. The importance of radioiodine uptake by the skin and hair in humans is most likely insignificant in the context of internal dosimetry, and the concentrations, if any, have not been measured. 


\section{Chapter III}

Kinetic Models and Calculation of Estimated Absorbed Doses

Radiopharmaceuticals used in nuclear medicine procedures are usually administered to patients by intravenous injection, ingestion, or inhalation. Once a radionuclide enters the bloodstream, its uptake and retention by organs or tissues within the body are influenced by many factors, including the chemical properties of the radiopharmaceutical and various physiological processes. In order to calculate radiation doses from the administration of radiopharmaceuticals, one must estimate the number of disintegrations occurring in different regions of the body. Mathematical models are thus used to describe the kinetics of the substance within the body and to permit the estimation of the number of disintegrations occurring within the organs or tissues of interest. The results of such models must then be combined with information about the physics of the radionuclide decay and energy absorption to estimate the radiation dose to the various body regions of interest.

\section{A. Compartmental Models}

When constructing a biological model, the ideal situation is to accurately describe the behavior of a tracer within a real biological system. However, any model is always only an approximation due to an imperfect understanding of the physiological processes occurring within the body. As noted in MIRD Pamphlet No. 12 (Berman 1977), 
"A substance introduced into a biological system undergoes changes of state due to transport and chemical reactions. Since detailed knowledge of the factors affecting these processes is seldom available, the observed kinetics are frequently modeled by simplified constructs which lump the biological details into a relatively small number of discrete states with transitions between them."

The compartments used in a model may thus represent a combination of anatomic regions or individual organs and the biologic mechanisms happening within and between them (Loevinger et al. 1991). The movement of the tracer from one compartment to another or to the outside environment is symbolized by arrows and is quantitatively described by transfer rate coefficients. The transfer rate coefficient(s) describe the rates at which materials are transferred within the system, by physical and biological processes. The modeling of tracer kinetics is based on the assumption that the tracer is detectable, exists in minuscule amounts compared to the tracee, and is closely related to the tracee in terms of physical and chemical properties.

There are several standard models often used to describe the behavior of a tracer in a biological system. One model commonly used is the mammillary model (Figure 3-1a). This model consists of a central compartment, usually representing blood or plasma, with material entering and leaving peripheral compartments via fixed or variable transfer rate coefficients. The peripheral compartments may represent any organ(s) or anatomic regions. Another form of model is the 
catenary model, which consists of a chain of compartments with material flowing from one compartment to the next, again by fixed or variable transfer rate coefficients (Figure 3-1b). International Commission on Radiological Protection (ICRP) in its Publication 30 (ICRP 1979) uses this model in describing the movement of material through the gastrointestinal tract. A complete biokinetic model describing the movement of a radiotracer within the body may employ either of these approaches, or a combination of mammillary and catenary approaches, as is most appropriate.

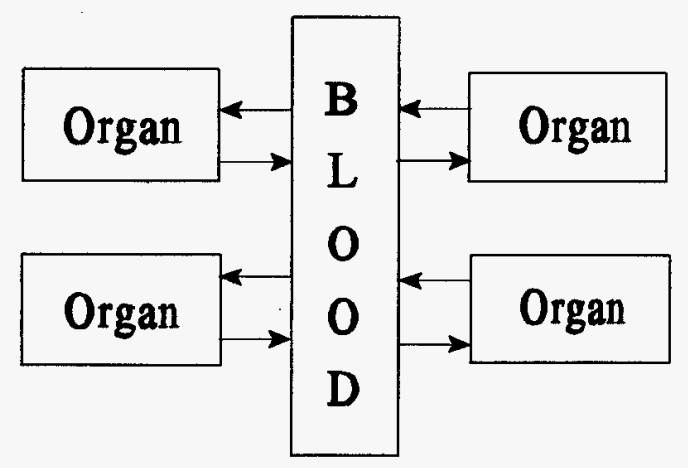

Figure 3-1a. Sample mammillary model for biokinetic analysis.

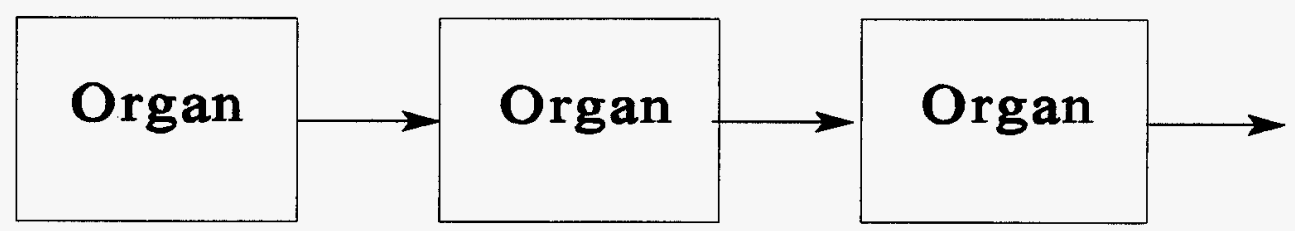

Figure 3-1b. Sample catenary model for biokinetic analysis. 


\section{B. Mathematical Model}

The design of a compartmental model gives a visual description of what may be occurring in a given system; however, to describe the behavior of the system quantitatively, mathematical descriptions of the tracer movement must be developed. A typical approach is to use coupled differential equations to describe the time dependent behavior of the tracer in all compartments. The two compartment system shown in Figure 3-2 will be used to illustrate the development of the associated differential equations. However, before solving the differential equations, some conditions must be defined for the system. First, the model in Figure 3-2 portrays a hypothetical biological system. The tracer is assumed to be radioiodine with a physical half-life of 8.04 days. The material leaving the system by physical decay is represented by $\mathrm{K}_{\mathrm{p}}$. The transfer rate coefficients, $\mathrm{k}(2,1)$ and $\mathrm{k}(1,2)$, represent the transport of material by means of biological processes occuring within the system. The transfer rate coefficient $k(2,1)$ describes the movement of material (tracer) from compartment 1 to compartment 2 and $\mathrm{k}(1,2)$ represents the transport of material from compartment 2 back to compartment 1 . Second, the radioactive decay of any nuclide is assumed to be independent of outside forces, thus physical decay is allowed to follow the laws of physics, i.e. decreases exponentially with time. The removal of radioactive material via biological processes, also functions independently, and is assumed to be exponential. In eliminating material, the body cannot differentiate between ordinary compounds and their radioactively labeled counterparts. Third, the fraction of administered activity in compartment 1 at time zero is 1.0 (instantaneous uptake), with no activity in compartment 2. 
The coupled differential equations for compartments 1 and 2 are described in equations 1 and 2.

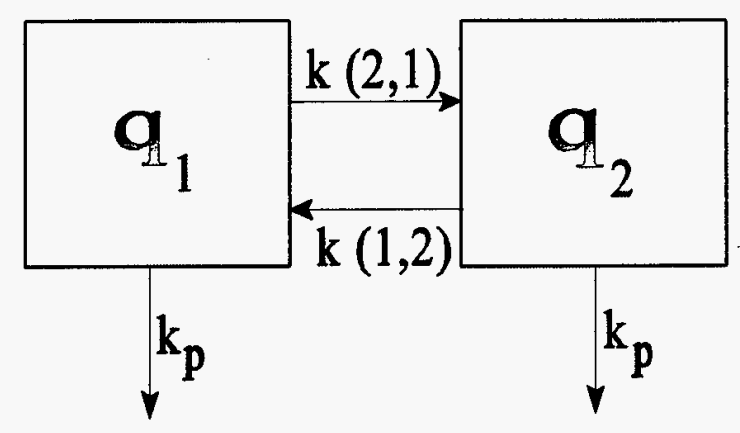

Figure 3-2. A two-compartmental model with designated transfer rate coefficients.

\section{Differential Equations:}

$$
\begin{aligned}
& \frac{d q_{1}}{d t}=k(1,2) q_{2}-\left[k(2,1)+k_{p}\right] q_{1} \\
& \frac{d q_{2}}{d t}=k(2,1) q_{1}-\left[k(1,2)+k_{p}\right] q_{2}
\end{aligned}
$$

where,

$$
\frac{d q_{t}}{d t}=\text { Rate of change of the amount of tracer i with respect to time. }
$$




\footnotetext{
$q_{\boldsymbol{1}}=$ Amount of tracer i in a compartment (units may be mass, activity, etc.).

$k(i, j)=$ Transfer rate coefficient $\left(\mathrm{t}^{-1}\right)$, the fraction of tracer i material transported per unit time from one compartment $(j)$ to another or to the outside environment
}

(i).

There are a variety of techniques available to solve the system of differential equations developed to describe any system. The substitution method, matrix method, and Laplace transformation method are three common techniques used to solve the equations and to obtain a series of equations which will describe the time dependent behavior of the tracer in both compartments. The first two, substitution and matrix, will be briefly described, and the Laplace transformation technique will be demonstrated. The three techniques described are equivalent and, if used correctly, will provide the same solutions.

\section{Substitution Method}

The substitution method allows for the transformation of a differential equation by means of solving and substituting a variable of one differential equation into the other. The second equation then becomes a second order differential equation which, when solved is in the form of a quadratic equation which contain solvable characteristic roots (Stabin 1993). The form of the solution is assumed to be a sum of exponential terms; these roots are the exponents of the 
individual terms (Stabin 1993). The coefficients of the terms are determined by applying the initial conditions of the problem to the differential equations, using the known roots.

\section{Matrix Method}

This method employs a matrix-based description of the differential equations, initial conditions, and solution. The solution of the system can be obtained by solving for the eigenvalues and eigenvectors (characteristic values - roots and coefficients) of the differential equation matrix (Zill 1989). Eigenvalues are scalar quantities, meaning they are characterized by single values and the magnitude of the quantity concerned (Zill 1989). An eigenvector is the solution corresponding to the appropriate eigenvalue.

\section{Laplace Transformation Method}

The Laplace transformation method converts each coupled differential equation to a coupled linear algebraic equation. The algebraic equations are then mathematically rearranged and solved to obtain the transforms of $\mathrm{q}_{\mathrm{i}}$. The inverse Laplace transform for each equation is then taken in order to obtain the solution of the differential equations. The Laplace transformation method is frequently used when solving coupled differential equations for systems containing more than three compartments. However, due to the complexity and time involved in solving larger models, computer programs are extensively used for this purpose. One such computer program, Simulation Analysis And Modeling (SAAM) (Resource Facility for Kinetic Analysis 1990) will be reviewed and discussed in the next section. 
The coupled differential equations and transformations for compartments 1 and 2 in Figure 3-2 are as follows:

\section{Differential equations:}

$$
\begin{aligned}
& \frac{d q_{1}}{d t}=k(1,2) q_{2}-\left[k(2,1)+k_{p}\right] q_{1} \\
& \frac{d q_{2}}{d t}=k(2,1) q_{1}-\left[k(1,2)+k_{p}\right] q_{2}
\end{aligned}
$$

\section{Transformations}

The Laplace method transforms a function $F(t)$ into a function of a parameter s.

$$
\begin{aligned}
& s F_{1}-q_{1}(0)=k(1,2) F_{2}-\left[k(2,1)+k_{p}\right] F_{1} \\
& s F_{2}-q_{2}(0)=k(2,1) F_{1}-\left[k(1,2)+k_{p}\right] F_{2}
\end{aligned}
$$

To simplify equations 3-3 and 3-4:

$$
\begin{aligned}
& k(2,1)=k_{1} \\
& k(1,2)=k_{2}
\end{aligned}
$$




$$
\begin{aligned}
& k(2,1)+k_{p}=k_{3} \\
& k(1,2)+k_{p}=k_{4}
\end{aligned}
$$

Solution for $q_{1}(t)$ :

Solving for and eliminating $F_{2}$ from the transformed differential equation:

$$
\begin{aligned}
& F_{2}=\frac{k_{1} F_{1}}{\left(s+k_{4}\right)} \\
& s F_{1}+k_{3} F_{1}=k_{2} \frac{\left(k_{1} F_{1}\right)}{\left(s+k_{4}\right)}+q_{1}(0)
\end{aligned}
$$

By mathematically rearranging the equation, and solving for $F_{1}$ :

$$
F_{1}=\frac{q_{1}(0)\left(s+k_{2}+k_{p}\right)}{\left[s^{2}+s\left(k_{2}+k_{1}+2 k_{p}\right)+k_{p}\left(k_{1}+k_{2}+k_{p}\right)\right]}
$$

The denominator is a quadratic equation in the form of $a x^{2}+b x+c=0$, thus the quadratic formula can be used to solve for the characteristic roots: 
where,

$$
\begin{aligned}
& a=1 \\
& b=k_{2}+k_{1}+2 k_{p} \\
& c=k_{p}\left(k_{1}+k_{2}+k_{p}\right) \\
& F_{1}=\frac{q_{1}(0)\left(s+k_{2}+k_{p}\right)}{[(s+\gamma)(s+\delta)]}
\end{aligned}
$$

Taking the inverse of the Laplace transform of $F(s)$ :

$$
q_{1}(t)=q_{1}(0)\left(\frac{\left[(a-\delta) e^{-\delta t}-(a-\gamma) e^{-\gamma t}\right]}{(\gamma-\delta)}\right)
$$

Since $a$ (where $a=k_{2}+k_{p}$ ), $\delta$, and $\gamma$ are constants, as determined below, variables A and B can substituted into equation 3-9:

$$
A=\frac{q_{1}(0)\left[\left(k_{2}+k_{p}\right)-\delta\right]}{(\gamma-\delta)} \quad B=\frac{q_{1}(0)\left[\left(k_{2}+k_{p}\right)-\gamma\right]}{(\gamma-\delta)}
$$


where,

$$
q_{1}(t)=A e^{-\delta t}+B e^{-\gamma t}
$$

Solution for $\mathrm{q}_{2}(\mathrm{t})$ :

Solving for $F_{1}$ from the transformed differential equations:

$$
\begin{aligned}
& F_{1}=\frac{\left[k_{2} F_{2}+q_{1}(0)\right]}{\left(s+k_{3}\right)} \\
& F_{2}\left(s+k_{4}\right)=k_{1} \frac{\left[k_{2} F_{2}+q_{1}(0)\right]}{\left(s+k_{3}\right)}
\end{aligned}
$$

By mathematically rearranging the equation and solving for $F_{2}$ :

$$
F_{2}=\frac{k_{1} q_{1}(0)}{\left[s^{2}+s\left(k_{2}+k_{1}+2 k_{p}\right)+k_{p}\left(k_{2}+k_{1}+k_{p}\right)\right]}
$$

By use of the quadratic equation, the denominator will have the characteristic roots $\gamma$ and $\delta$ : 
where,

$$
\begin{aligned}
& a=1 \\
& b=k_{2}+k_{1}+2 k_{p} \\
& c=k_{p}\left(k_{2}+k_{1}+k_{p}\right) \\
& F_{2}=\frac{k_{1} q_{1}(0)}{[(s+\gamma)(s+\delta)]}
\end{aligned}
$$

Taking the inverse of the Laplace transform of $\mathrm{F}(\mathrm{s})$ :

$$
q_{2}(t)=k_{1} q_{1}(0)\left(\frac{\left[e^{-\gamma t}-e^{-\delta t}\right]}{(\delta-\gamma)}\right)
$$

Since $\mathrm{k}_{1}, \mathrm{q}_{1}(0), \gamma$, and $\delta$ are constants, as determined below, variables such as $C$ and $D$ can be substituted into equation 3-16:

$$
\begin{aligned}
& C=D=\frac{k_{1} q_{1}(0)}{(\delta-\gamma)} \\
& q_{2}(t)=C e^{-\gamma t}-D e^{-\delta t}
\end{aligned}
$$


Equations 11 and 18 may be integrated over a specific time interval to estimate the number of disintegrations occurring in each compartment. These integrals are then related to the dose absorbed by various tissues within the body, as described below.

\section{Absorbed Dose}

Methods to calculate the absorbed dose from internally distributed radionuclides can be found in ICRU Report 32 (1979), ICRP 30 (1979), and NCRP Report 84 (1985). However, the MIRD method is the technique most utilized today in determining the dose to organs or tissues from radiopharmaceuticals (ICRP 1988). The MIRD method was adopted and recommended by the MIRD Committee of The Society of Nuclear Medicine and in 1991, Loevinger, Budinger, and Watson, in collaboration with the MIRD Committee, published the "MIRD Primer For Absorbed Dose Calculations" (Loevinger et al. 1991). This schema demonstrates and provides the information required to calculate the absorbed dose to the sites of interest within the body. The MIRD method will be used in estimating absorbed doses in this study.

The MIRD schema describes the absorbed dose as the amount of energy from ionizing radiation that is deposited per unit mass at the site of interest. The anatomical region where disintegrations occur is referred to as the source region $\left(r_{\mathfrak{h}}\right)$. Specific regions irradiated from the activity contained in the source regions are referred to as target regions $\left(\mathrm{r}_{\mathrm{k}}\right)$. The extent of the dose to the target organ depends on the physical characteristics of the radionuclide and the location and geometrical relationship between the source and the target organs. Figure 3-3, taken 
from the MIRD Primer (Loevinger et al. 1991), illustrates the source and target region concept for three radiopharmaceuticals. It should be noted, due to self-irradiation, that source regions are always considered target regions, and that a system may contain more than one source region.

In estimating the absorbed dose to source and target regions from a radiopharmaceutical, the MIRD schema combines the biokinetics of the radiopharmaceutical and the physical properties of the radionuclide. The biokinetics refers to the distribution and retention of the radiopharmaceutical within the body. The physical properties include the decay properties of the radionuclide, the fraction of energy absorbed by the target organ, and the mass(es) of the organ(s) of interest.

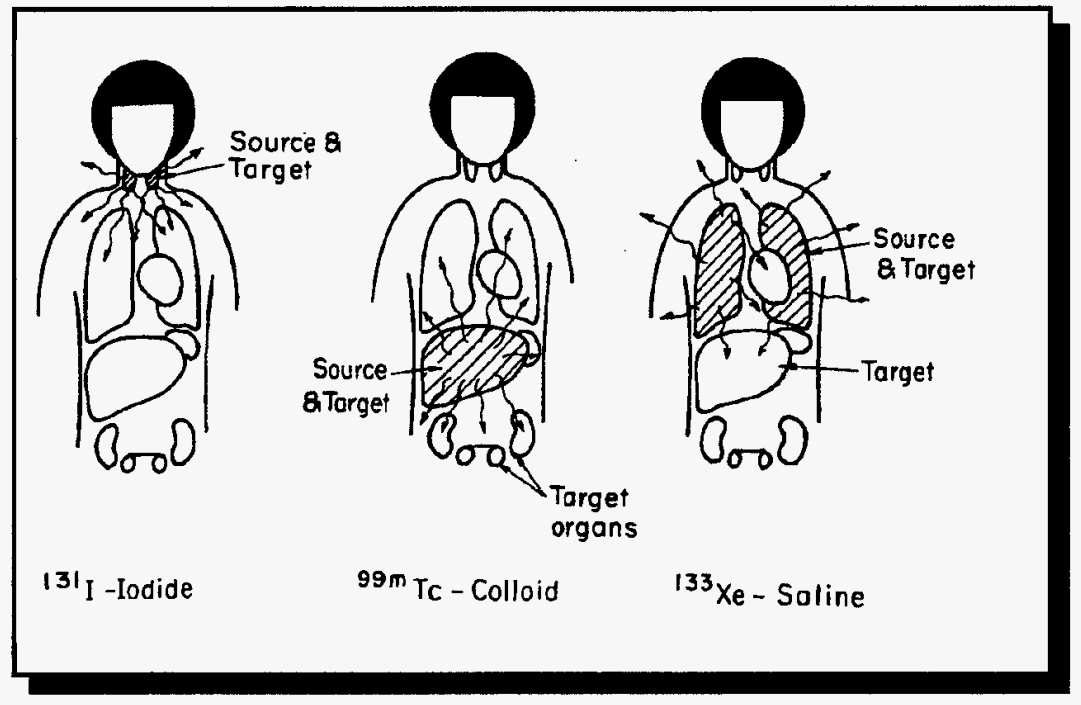

Figure 3-3. Designated source and target regions for three radiopharmaceuticals used in nuclear medicine procedures (Loevinger et al. 1991). 
The MIRD schema describes the mean absorbed dose delivered to the target region from the source region as:

$$
\bar{D}\left(r_{k} \leftarrow r_{h}\right)=\tilde{A}_{h} S\left(r_{k}+r_{h}\right)
$$

where,

$\bar{D}=$ The mean absorbed dose to the target region $\left(\mathrm{r}_{\mathrm{k}}\right)$ from the source region $\left(\mathrm{r}_{\mathrm{h}}\right)$ (rads).

$\tilde{A_{h}}=$ The cumulated activity (the integral of the time activity curve) in the source region ( $\mu \mathrm{Ci}$-hours).

$S=$ The dose to the target region $\left(\mathrm{r}_{\mathrm{k}}\right)$ from unit cumulated activity in the source region $\left(r_{h}\right)(\operatorname{rad} / \mu$ Ci-hours).

where,

$$
S\left(r_{k}-r_{h}\right)=\sum_{i} \Delta_{i} \Phi_{i}
$$

$\Delta_{t}=$ The mean energy emitted per nuclear transition for radiation $\mathrm{i}(\mathrm{rad}-\mathrm{gram} / \mu \mathrm{Ci}-$ hours).

$\Phi_{t}=$ The specific absorbed fraction (the fraction of energy emitted in a source region that is absorbed in a target region, per unit mass) for radiation $\mathrm{i}\left(\mathrm{g}^{-1}\right)$. 
Equation 3-19 describes the mean absorbed dose to a target region when the radiopharmaceutical localizes in one area and irradiates only one target region. However, this is usually not the case for most radiopharmaceuticals. Radioactivity normally spreads throughout the body and involves several source regions contributing to the absorbed dose of several targets. Also, it is sometimes more convenient to describe the absorbed dose to the target by the introduction of a new parameter known as $\tau$, the residence time. The residence time is described as the quotient of the cumulated activity in the source region divided by the administered activity:

$$
\tau=\frac{\tilde{A}_{h}}{A_{0}}
$$

Residence time has units of time $(\mu \mathrm{Ci}-\mathrm{hr} / \mu \mathrm{Ci} \boxminus \mathrm{hr})$

Thus equation 3-22 allows for the summation of all the residence times and S-values:

$$
\bar{D}\left(r_{k}+r_{h}\right)=A_{0} \sum_{h} \tau_{h} S\left(r_{k}-r_{h}\right)
$$

This equation thus defines the total dose to one target region. When similar equations are defined for all target regions, the dosimetry for the system is completely described. 
1. Distribution and Retention of the Radiopharmaceutical

The residence time, as described in equation 3-21, depends on the distribution and retention of the radiopharmaceutical (Loevinger et al. 1991). The biokinetics for a radiopharmaceutical are related to many factors, some of which are not always well known or understood. The distribution and retention of a radiopharmaceutical is dependent on chemical properties, metabolic processes, and potentially many other factors (Loevinger et al. 1991).

Radionuclides attached to different compounds can localize in various regions of the body. Figure 3-4, from the MIRD Primer (Loevinger et al. 1991), illustrates the distribution sites of the radionuclide ${ }^{99 \mathrm{~m}} \mathrm{Tc}$ when labeled to different compounds.

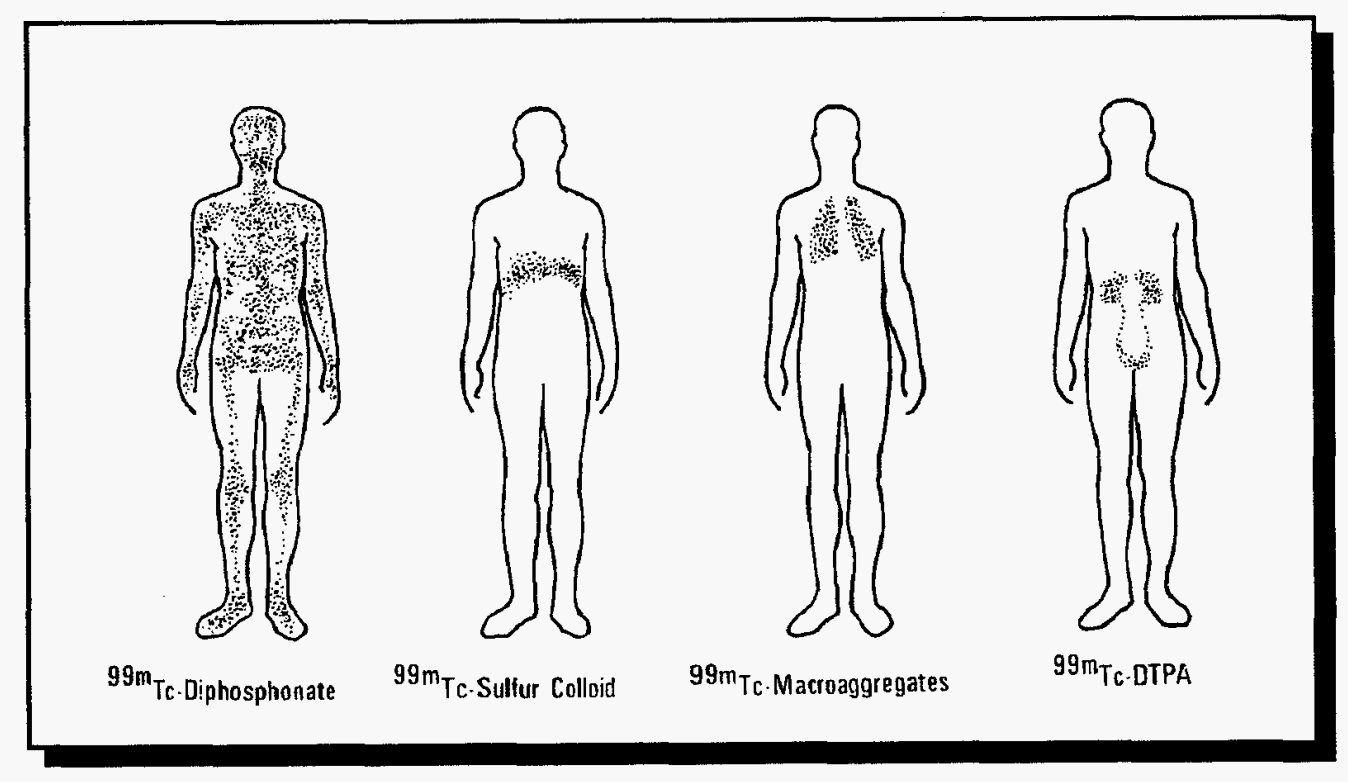

Figure 3-4. Distribution sites for ${ }^{99 \mathrm{~m}} \mathrm{Tc}$ when labeled to different compounds (Loevinger et al. 1991). 
The residence time in the source region is thus an estimate based on the time-dependent behavior of the radiopharmaceutical within the body and can be defined as the integral of the sum of all the nuclear transitions that occur in the source region during a time period (Loevinger et al. 1991).

$$
\tilde{A}_{h}=\int A_{h}(t) d t
$$

where,

$$
\begin{aligned}
A_{h}(t)= & \text { The number of nuclear transitions occurring in a region as a function of } \\
& \text { time. }
\end{aligned}
$$

Setting the lower limit of the integral to zero and the upper limit to infinity allows for the complete physical decay and biological removal from the source region (Loevinger et al. 1991).

To illustrate the concept of residence time, Figure 3-5, taken from the MIRD Primer (Loevinger et al. 1991), represents a time-activity curve for an organ. The activity in the organ at time 0 is equal to zero and then increases as the time increases. At a certain time, the activity in the organ reaches a maximum and then declines as the time continues. The accumulated activity in the organ is represented by the area under the curve. By the definition of the residence time, the rectangle depicted in the figure has an area equal to the integral of the time activity curve (Loevinger et al. 1991). 
Sometimes the administered activity is assumed to be taken up by the source organ very quickly and the maximum activity may be assumed to occur at time zero (Figure 3-6). Thus, it can be assumed that the activity may be represented by a function that decreases continually over time due to the physical and biological removal of material.

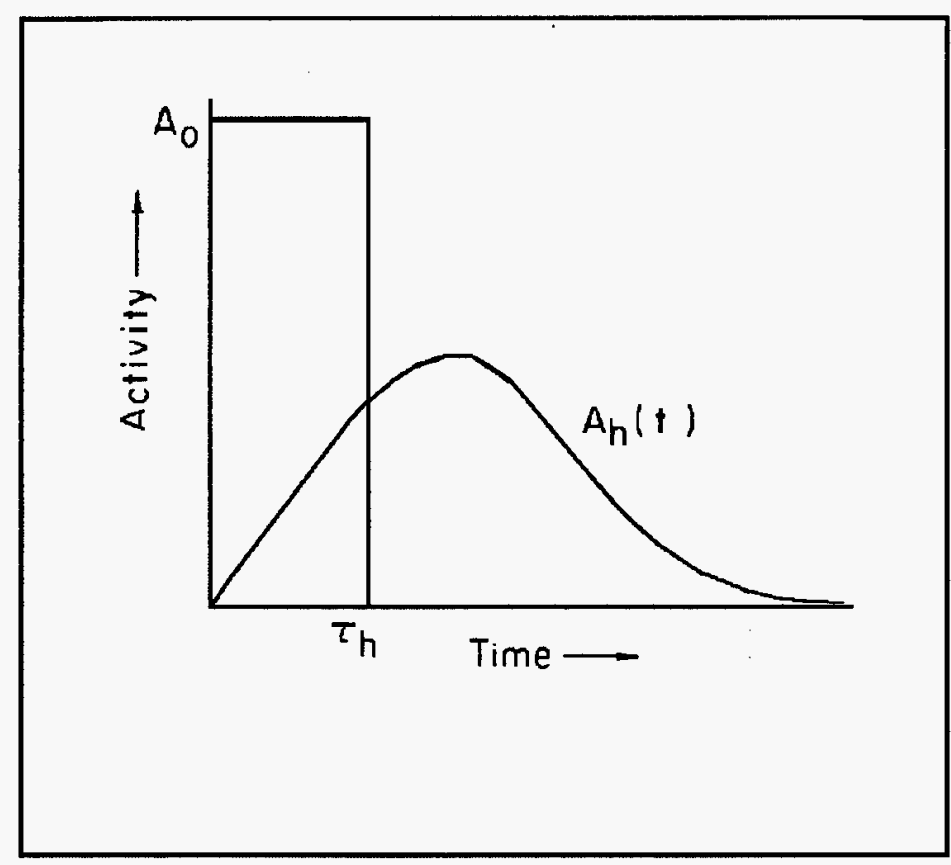

Figure 3-5. Illustration of residence time with the area under the time-activity curve representing the accumulated activity which is equal to the area of the rectangle (Note: No activity at time $=0$ ) (Loevinger et al. 1991). 


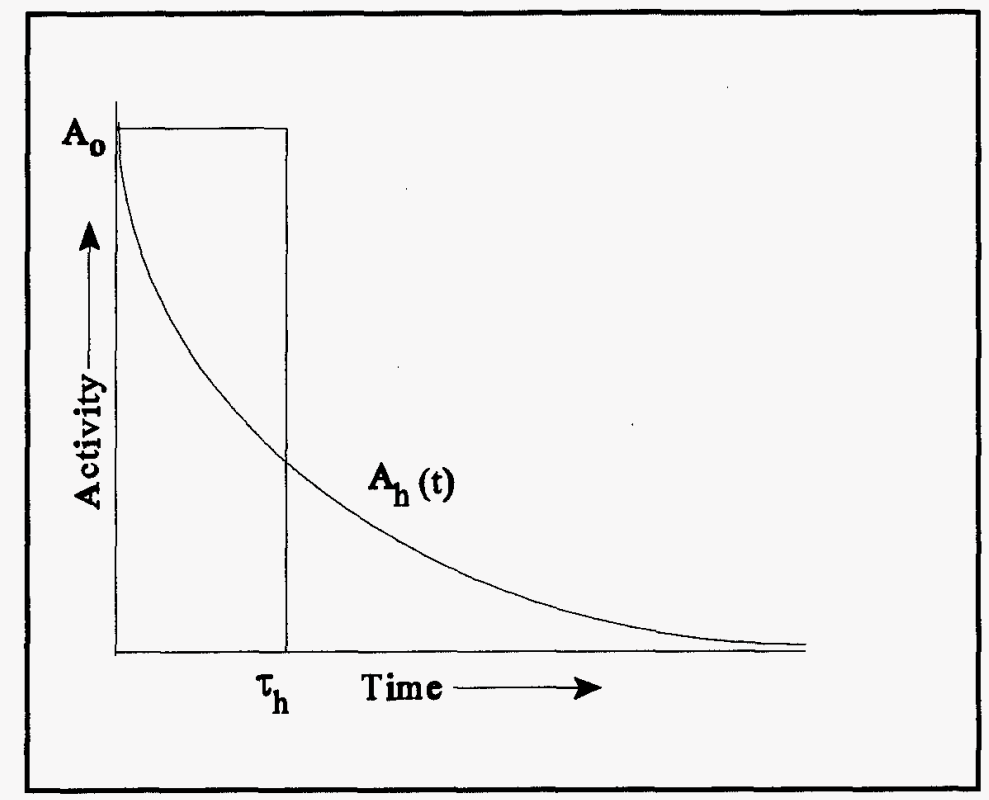

Figure 3-6. Time-activity curve representing instaneous uptake by the source organ (Loevinger et al. 1991).

To establish the appropriate time-activity curve for a given radionuclide, a series of measurements are usually needed. The measurements can represent either the retention or excretion of activity from a source region or the whole body. Collecting data on the distribution and retention of a radiopharmaceutical in the human body is always desired, but is not always possible. Animal data, when appropriate, can be collected and extrapolated to humans; however, many assumptions are usually made, thus increasing the uncertainty in the final dose estimates.

The use of phantoms is another source of uncertainty in internal dose estimates. A phantom is a standard model designed to represent the anatomical structures and composition of tissues in the human body. In the past, only one phantom existed, representing standard man, but today, phantoms exist for males, females (pregnant and nonpregnant), and children. 
Once a series of measurements has been acquired, a method is needed to estimate the area under the time-activity curves. One method, compartmental modeling, was discussed at the beginning of this section; however, there are other methods. Two such common techniques used in estimating the residence time are direct integration and least square analysis. Several numerical techniques, such as the trapezoidal method, Simpson's method, and the Gauss Quadrature method, can be utilized to directly integrate measured values. Although these methods are quite simple in estimating the area under the time-activity curve, they do not furnish much information regarding the system as a whole (Stabin 1993). The least square analysis method fits a curve to the plotted measurements and then relates the curve to a mathematical function, usually a set of exponential terms, since many biological systems are represented by this process (Stabin 1993). The exponential functions can then be directly integrated to acquire the residence time.

\section{Physical Properties of the Radionuclide}

The physical properties of most radionuclides have been well established. These properties are represented in MIRD equation 3-22 within the S-value, the mean absorbed dose to a target organ per unit cumulated activity in the source organ (Loevinger et al. 1991). The Svalue includes the average energy and abundance of each emission, the fraction of energy that is absorbed in the target organ from the source organ, and the mass of the target organ. Currently there are published S-value tables for many radionuclides and standard organ pairs; however, for those values that do not exist in the literature, special S-values may need to be calculated. The Svalue is described as follows: 


$$
S\left(r_{k}+r_{h}\right)=\Delta_{i} \Phi_{i}=k \sum_{i} n_{i} E_{i} \frac{\left[\phi_{i}\left(r_{k} \leftarrow r_{h}\right)\right]}{m_{t}}
$$

where,

$$
\begin{aligned}
& \Delta_{t}=k \sum_{t} n_{t} E_{t}=\text { The total mean energy emitted per nuclear transition } \\
& \text { (rad-gram / } \mu \text { Ci-hour). } \\
& \Phi_{t}=\frac{\Phi_{l}}{m_{t}}=\text { The absorbed fraction of i-type radiation in the target organ per unit } \\
& \text { mass of the target }\left(\mathrm{g}^{-1}\right) .
\end{aligned}
$$

where,

$k=$ A constant that depends on the units selected for a given problem.

$n_{\boldsymbol{l}}=$ The number of particles of type $\mathrm{i}$ radiation emitted per nuclear transition (particles / transition).

$E_{t}=$ The mean energy per particle of type i radiation $(\mathrm{MeV})$. 


$$
\phi_{t}=\frac{\text { Energy absorbed by the target }}{\text { Energy emitted by source }}
$$

or the absorbed fraction of the energy emitted by the source organ that is absorbed in the target.

$m_{t}=$ The mass of the target organ (grams).

The absorbed fraction, $\phi$, not only depends on the type and energy emitted by the radiation, but also on its absorption characteristics and the size and shape of the organs of interest (Loevinger et al. 1991). The absorption characteristics of the radiation in the MIRD schema are simply described in terms of the radiations being "penetrating" or "non-penetrating." High energy photons are considered "penetrating" radiation due to the range they can travel before interacting and depositing their energy in a medium. Beta particles, electrons, and photons of energies less than $20 \mathrm{keV}$ are considered "non-penetrating" radiations, as most of their energy is deposited at the source site (Cloutier and Watson 1977). Figure 3-7, from the MIRD Primer, visually describes the concept of absorbed fraction. The absorbed fraction for "non-penetrating" radiation is normally 1.0 if the source and target regions are the same. If the target and source regions are different, then the absorbed fraction is 0 . The absorbed fraction for "penetrating" radiation can range from 0 to 1 and depends on the photon energy and the geometry of irradiation. 


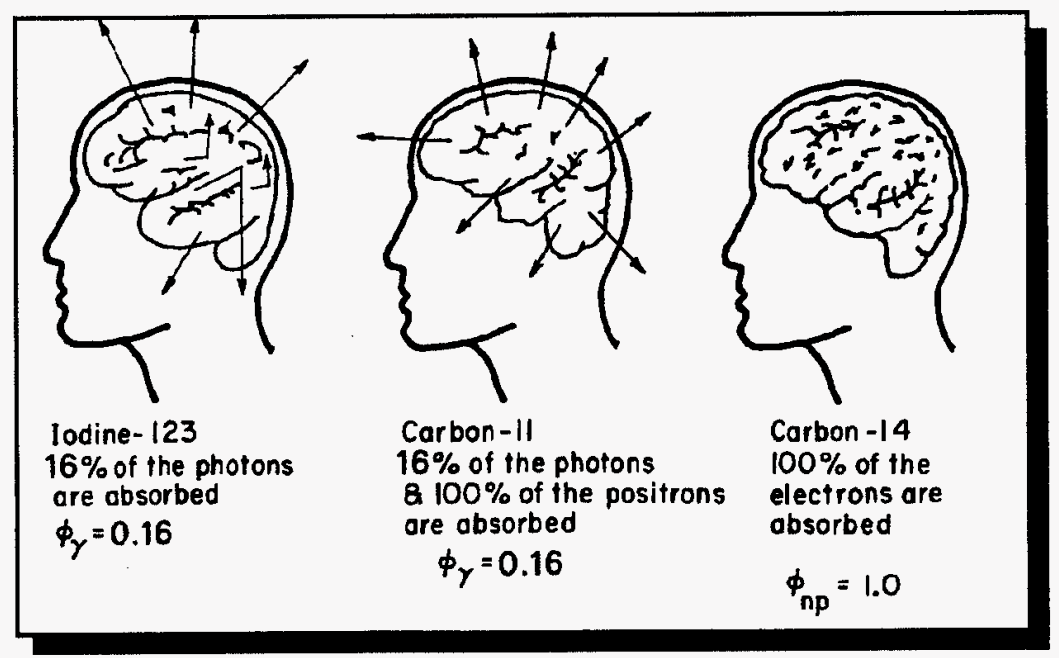

Figure 3-7. The concept of absorbed fraction, $\phi$, as demonstrated for penetrating and nonpenetrating radiations (Loevinger et al. 1991).

Absorbed fractions for photons of various energies and designated source-target pairs in a reference adult have been calculated and can be found in MIRD Pamphlet No. 5 (Snyder et al. 1978). Similar values have been estimated and reported for phantoms representing children of various ages (Cristy and Eckerman 1987) and the adult female at different stages of pregnancy (Stabin et al. 1995). The standard technique in calculating the absorbed fraction is the Monte Carlo method. The Monte Carlo method estimates the amount of energy absorbed by utilizing information concerning the size, shape, and composition of the source organ, the energy of the photon, and the type of interaction of the photon. The Monte Carlo method takes advantage of the fact that photon interactions within a medium is regulated by probababilistic laws rather than deterministic (Cember 1985). Thus through random processes, the photon direction, distance it 
travels, and type of interaction, can be determined. When the Monte Carlo method fails to provide reliable absorbed fraction estimates, other techniques may be employed, such as the reciprocity method and build-up method. 


\section{Chapter IV}

\section{Model Analyses}

Simulation is a process that uses computers to build a model to imitate a system (Madu and Kuei 1993). Model coding is just one facet of simulation modeling and is considered a "sophisticated systems analysis" (Madu and Kuei 1993). Computer modeling programs are used extensively to assist in the development and analysis of kinetic data. The basic approach involved in employing such programs is to create and solve coupled differential equations from the model's structure, and allow modification of the estimated transfer rate coefficients until an "acceptable" fit is obtained.

However, since models rarely duplicate exactly the system of interest, the predicted outcome may be built on a foundation of theory, assumptions, or observed relationships (Kirchner 1994). Although the results from a model may provide parameters and an "acceptable fit" to the data, it is essential to understand the limitations associated with them (or "the model"). Establishing how well some specified model represents the real system is important, in that it determines if the chosen model is appropriate, and how well a given solution models the real system. The sensitivity to the data, the quality of its predictions and the uncertainty in its predictions must be based upon extensive verification, validation, sensitivity and uncertainty analyses (Kirchner 1994). 


\section{A. Verification Analysis}

Verification analysis is a method of testing the internal consistency of a computer program and allows the computer code to be tested for programmatic and data entry errors. For example, a discrepancy between the observed and predicted values may be caused by one or more processes involved in the building of a model. Performing a verification analysis for the program eliminates the computer code as the source of error, thus allowing the user to focus on other areas of concern. The verification process will be demonstrated using a computer code and various models at the end of this section.

The terms "actual," "observed," and "predicted" are often interchanged and are used loosely in many published texts and journal articles; thus the real meaning of the terms may be misunderstood by the reader. The term "actual" should only be used when the value is known to be accurate or true, or if the solution is known to be exact. Rarely a value is considered "actual" in that if the true answer is known, then there would be no need to predict values by the use of a model. "Observed" values are measurements taken from the real system. Observed data is not exact and is subject to error, thus are considered to be best estimates. Finally, the data generated by the use of a model is considered to be the "predicted" values.

B. Validation Analysis

Validation analysis compares the observed data to the performance predicted by the simulation model. Determining the accuracy and credibility of a model, especially when conducted over time 
and under varied situations, depends on how close the observed and predicted values correspond (Madu and Kuei 1993).

There are three methods to test the validity of a model (Kirchner 1994):

1. Establish a high face validity for the model (i.e. have those familiar with the real system review the model).

2. Test assumptions used in the model, such as structure, pathways, parameter values, etc.

3. Quantitatively compare the predicted values to observed or actual values of an independent data set.

The first approach, establishing face validity, involves review by those familiar with the system structure, form of equations, and parameter values used in the model. This can be accomplished by publication of the model in the open literature, or by other peer associated activities, such as informal, formal presentation at a specific meeting, etc. (Kirchner 1994).

As previously mentioned, detailed information concerning many biological systems is often unavailable, thus, some assumptions must usually be made to develop a complete model structure. These assumptions are then incorporated into the model and its results.

A second approach to the validation process involves a means of testing these assumptions. The ideal situation is to test the assumptions empirically; i.e. verify the assumptions by direct 
observation or experience (Kirchner 1994). However, empirical testing is not always feasible, especially when modeling biological systems. When possible, it is useful to experiment with the structure of the model. This can be done by increasing or decreasing the compartments and/or parameters used in the model. Model comparison testing can also be conducted by comparing the results from models using different assumptions (Kirchner 1994). For example, the assumptions involved in the parameter values can be changed and the effects on the results be evaluated.

The final approach to be used is a quantitative comparison in which deviations between the model's output and observed data from the real system are measured. Statistical tests can be performed to evaluate the accuracy of the model to the real system (Madu and Kuei 1993).

\section{Sensitivity Analysis}

Depending on the system, the structure of a model can be simple, containing one or two compartments, or complex, containing numerous compartments with various pathways. Whichever the case, the importance of each compartment, parameter, or process occurring within the model can be evaluated using sensitivity analysis. Sensitivity analysis assesses the importance of different components to the model's performance.

Sensitivity analysis may be used to: (1) Provide a better understanding of the model's behavior, (2) help select and prioritize individual parameters for study when conducting a simulation, and (3) help improve the model's predictive ability by reducing the uncertainty associated with the parameters of highest sensitivity (Kirchner 1994). 


\section{Uncertainty Analysis}

Uncertainty analysis is considered a powerful tool for evaluating a model's predictions. Determining the degree of uncertainty in the results of the model is important to consider in that it establishes the bounds within which the reported results are known, identifies the results which are well established and those which are not, and allows interpretation of the model's results against any measured data.

One source of uncertainty in a model lies within the adjustable model parameters. Depending on the system, the uncertainty may be minimal and may be disregarded; however, most parameters will have many associated uncertainties that play an important role in the outcome of the model (Kirchner 1994).

The two major causes of parameter uncertainty are:

1. Natural variability in the parameter

2. Lack of knowledge about a parameter

Natural variability is caused by assuming the parameters vary across space or time in a stochastic fashion. Depending on the situation being modeled, natural variability most often plays a minimal role in uncertainty. However, for example, the variability may be large when considering individuals, as opposed to populations (Kirchner 1994). 
The second cause of uncertainty to consider, and the more dominant, is the lack of knowledge in fully understanding the parameters values or the system that is being modeled (Whicker and Schultz 1982). Knowledge can be improved by gathering all possible documentation pertaining to the system in question and by on-going research.

The most common technique used for uncertainty analysis is the Monte Carlo method. The Monte Carlo method allows the parameters and observed data to be studied as probability distributions instead of single numbers (Whicker and Schultz 1982). The Monte Carlo method involves running repeated simulations in order to obtain a probability distribution of output variables. The standard deviation, mean, and variance can then be determined from the randomly distributed variables (Whicker and Schultz 1982).

The significance of conducting each analysis should be considered when modeling the behavior of a real system. Although it is beyond the scope of this paper to present the reader a detailed means of conducting such analyzes, the performance and capabilities of a simulation computer code will be verified using two known models. Uncertainty analysis, as previously discussed, will be demonstrated in the remaining section of this paper.

\section{E. Simulation, Analysis and Modeling(SAAM)}

SAAM is a digital simulation computer code designed as a tool for the study and analysis of data regarding model building (Berman and Weiss 1978). SAAM was developed primarily for the 
biomedical community for modeling biological systems; however, it may also be used for other systems of interest (Berman and Weiss 1978).

The basic approach used by SAAM is to describe a model in the form of mathematical equations or functions, given that analytical or numerical solutions exist. SAAM utilizes a least squares fitting procedure to adjust parameter values within their mathematical functions so that the model results adequately fit observed data about the system. The parameter values are initially set by the user, and the program iteratively adjusts the parameter values by attempting to minimize the difference between the predicted and observed values (Berman et al. 1968).

To verify the ability of SAAM as a simulation modeling code, tests were performed and analyzed using two known biological models. These tests were conducted with the assistance of the Radiation Internal Dose Information Center (RIDIC), a federally funded research and service center in Oak Ridge, Tennessee. RIDIC provides information concerning internal radiation dose from radiopharmaceuticals and other internally incorporated radionuclides to physicians, researchers, pharmaceutical manufacturers, and government agencies. RIDIC also strives to improve and develop new models for both physical and biological processes affecting internal radiation dose estimates.

1. ICRP Publication 30 Gastrointestinal and Lung Models

ICRP Publication 30 describes two standard kinetic models, the lung and gastrointestinal (GI) tract models. The GI model consists of 4 main compartments, which describes the transfer of 
ingested radioactive material as it passes through the GI tract and/or is transferred to the body fluids (Figure 4-1 and Table 4-1). The lung model is divided into 10 compartments and describes the respiratory system in relationship to the inhalation, retention, and clearance of radioactive aerosols (Figure 4-2).

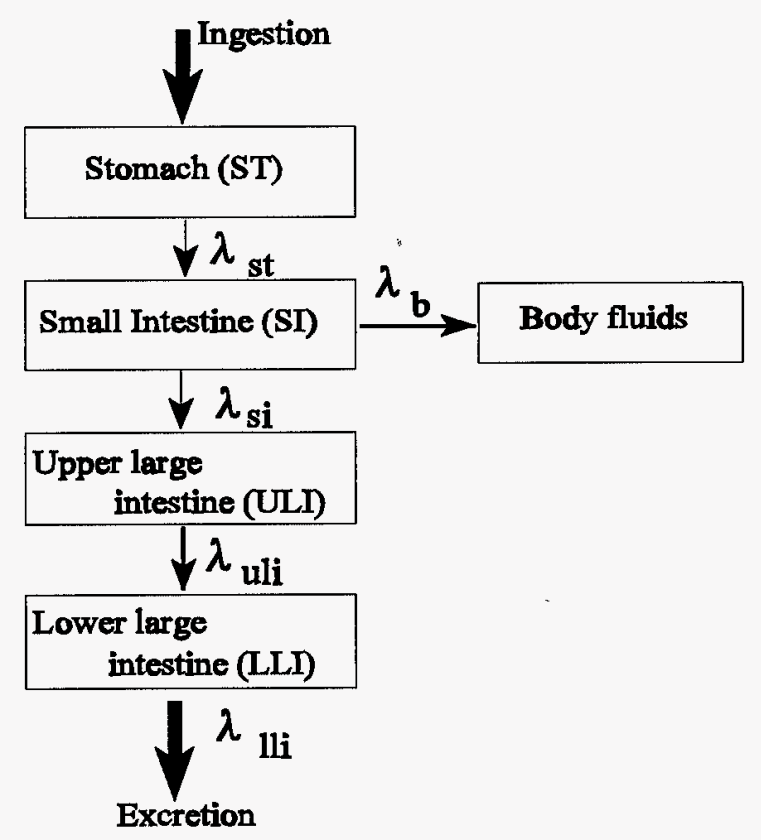

Figure 4-1. ICRP 30 GI tract kinetic model.

Table 4-1. Initial conditions and transfer rate coefficients for standard GI tract model for ${ }^{123} \mathrm{I}$ sodium iodide.

\begin{tabular}{|c|c|c|}
\hline Compartment & $\begin{array}{c}\text { Fraction of material at } \\
\text { time }=0\end{array}$ & $\lambda$ (hours $^{-1}$ ) \\
\hline Stomach (ST) & 1 & 1.0 \\
\hline Small Intestine (SI) & 0 & 0.25 \\
\hline Upper Large Intestine (ULI) & 0 & 0.0769 \\
\hline Lower Large Intestine (LLI) & 0 & 0.0417 \\
\hline
\end{tabular}




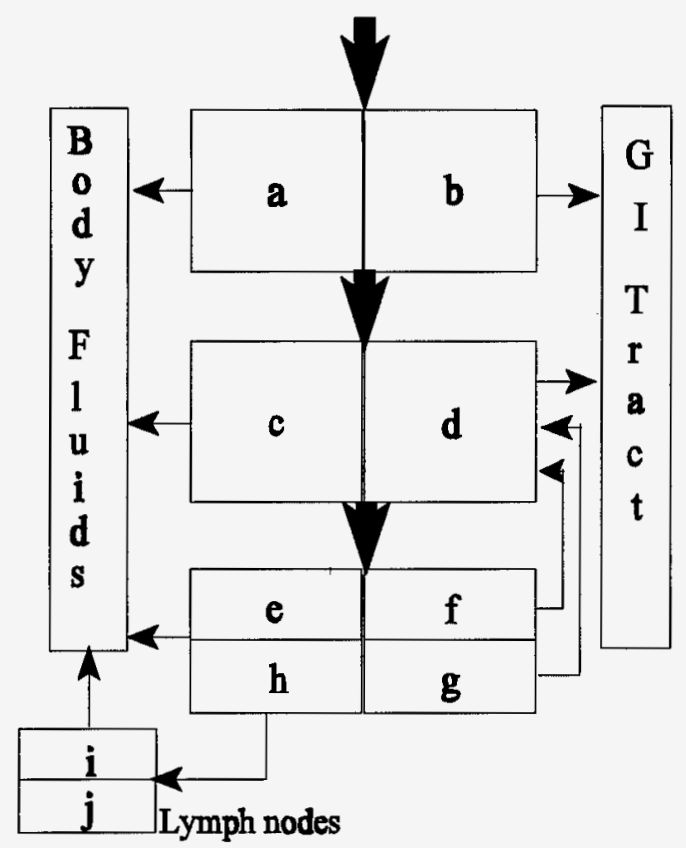

Figure 4-2. ICRP 30 lung model.

The ICRP 30 GI and lung models were implemented in the SAAM software (Version 31). In verifying SAAM, for each system, the differential equations were solved analytically for the activity in each compartment as a function of time, using the radionuclide ${ }^{123} \mathrm{I}$, with half-life of 13.2 hours. To compare the results, a ratio of the predicted values, generated by SAAM, and the actual values, for the stomach and lower large intestine compartments, and compartment $d$ of the lung model, was determined (See Appendix A for predicted and actual values) (Table 4-2 and 4-3).

A ratio greater than 1.0 means that the model predictions were larger than the actual results, a ratio less than 1.0 means that the model predictions were less than the actual results, and a ratio 
equal to 1.0 indicates an exact agreement within the predicted and actual values. The results reveal a ratio of 1.000 at time $(t)$ for the stomach and the lung $d$ compartments, and a range from 1.000 to 0.997 for the lower large intestine compartment. It appears SAAM was in exact agreement for the stomach and lung $d$ compartments, and under predicted the values for the lower large intestine compartment by up to $0.3 \%$. Overall, this difference is considered insignificant, and may possibly be due to rounding errors, and/or to an error in the numerical solution from SAAM.

Table 4-2. Predicted/Actual ratio over time for the stomach and lower large intestine compartments for the standard GI model using ${ }^{123} \mathrm{I}$ sodium iodide as the tracer.

\begin{tabular}{|c|c|c|c|c|c|}
\hline Time (hours) & $\begin{array}{c}\text { ST P/A } \\
\text { ratio }\end{array}$ & $\begin{array}{c}\text { LLI P/A } \\
\text { ratio }\end{array}$ & Time (hours) & $\begin{array}{c}\text { ST P/A } \\
\text { ratio }\end{array}$ & $\begin{array}{c}\text { LLI P/A } \\
\text { ratio }\end{array}$ \\
\hline 1 & 1.000 & 1.000 & 30 & $*$ & 0.998 \\
\hline 2 & 1.000 & 0.999 & 35 & $*$ & 0.998 \\
\hline 3 & 1.000 & 0.999 & 40 & $*$ & 0.998 \\
\hline 4 & 1.000 & 0.999 & 45 & $*$ & 0.998 \\
\hline 5 & 1.000 & 0.999 & 50 & $*$ & 0.998 \\
\hline 8 & 1.000 & 0.999 & 75 & $*$ & 0.998 \\
\hline 10 & 1.000 & 0.999 & 100 & $*$ & 0.998 \\
\hline 15 & 1.000 & 0.999 & 125 & $*$ & 0.997 \\
\hline 20 & 1.000 & 0.998 & 150 & $*$ & 0.997 \\
\hline 25 & 1.000 & 0.998 & & & \\
\hline
\end{tabular}

* Values too small to be meaningfully studied 
Table 4-3. Predicted/Actual ratio over time for compartment d of the lung model using ${ }^{123} \mathrm{I}$ sodium iodide as the tracer.

\begin{tabular}{|c|c|c|c|}
\hline Time (hours) & P/A ratio & Time (hours) & P/A ratio \\
\hline 0 & 1.000 & 24 & 1.000 \\
\hline 1 & 1.000 & 28 & 1.000 \\
\hline 4 & 1.000 & 32 & 1.000 \\
\hline 7 & 1.000 & 36 & 1.000 \\
\hline 10 & 1.000 & 40 & 1.000 \\
\hline 13 & 1.000 & 44 & 1.000 \\
\hline 16 & 1.000 & 48 & 1.000 \\
\hline 20 & 1.000 & & \\
\hline
\end{tabular}

A graphical representation illustrating the activity in the above organ compartments as a function of time was generated and compared to the results predicted by SAAM (Figures 4-3, 4-4 and 4-5). Based on the above test, SAAM appears to have correctly solved the differential equations and provide accurate results for the GI and lung models.

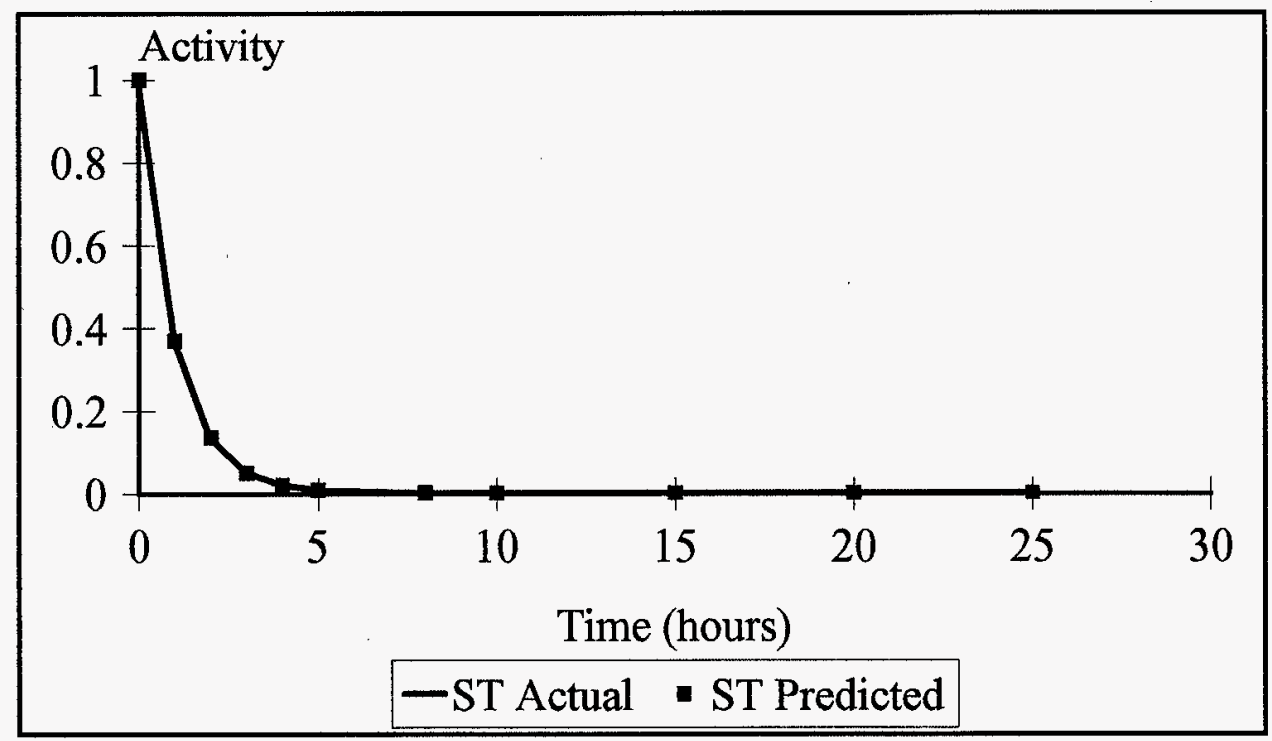

Figure 4-3. Activity as a function of time based on the analytical solution and SAAM 31 results for stomach compartment. 


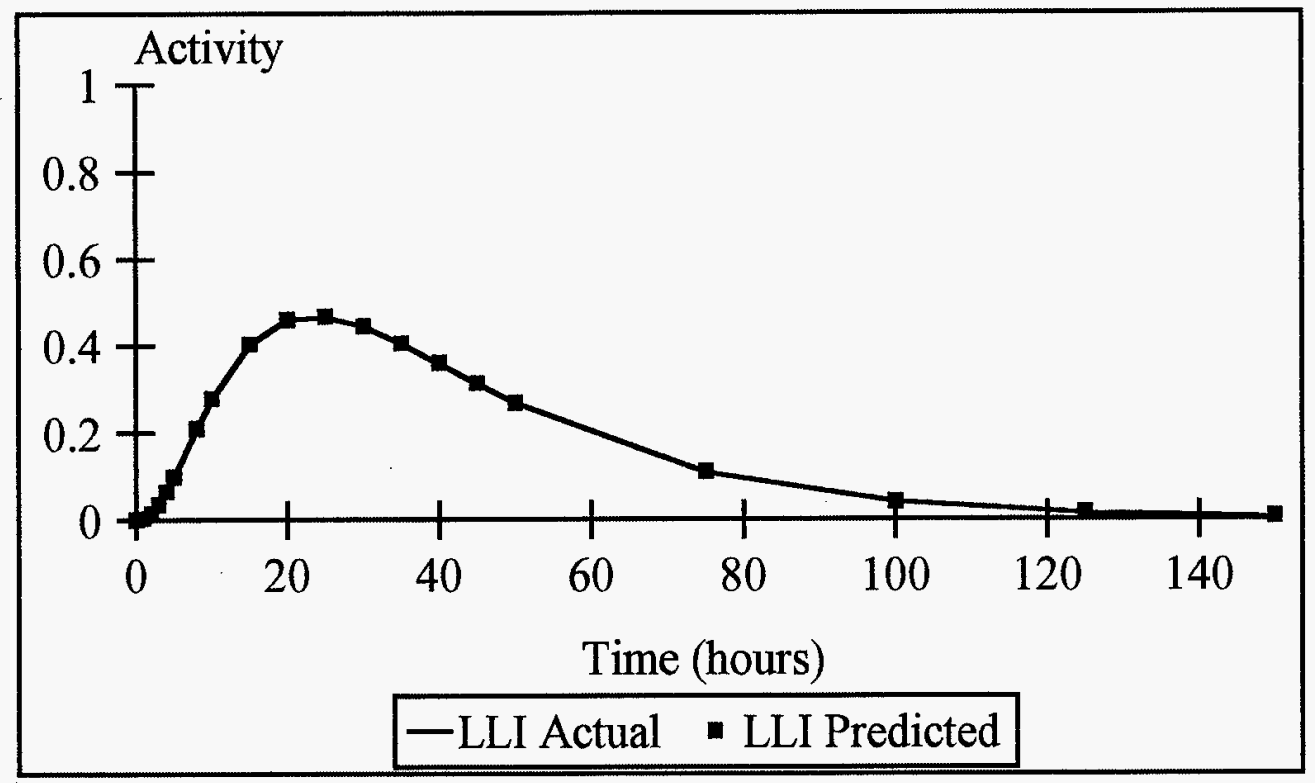

Figure 4-4. Activity as a function of time based on the analytical solution and SAAM 31 results for lower large intestine.

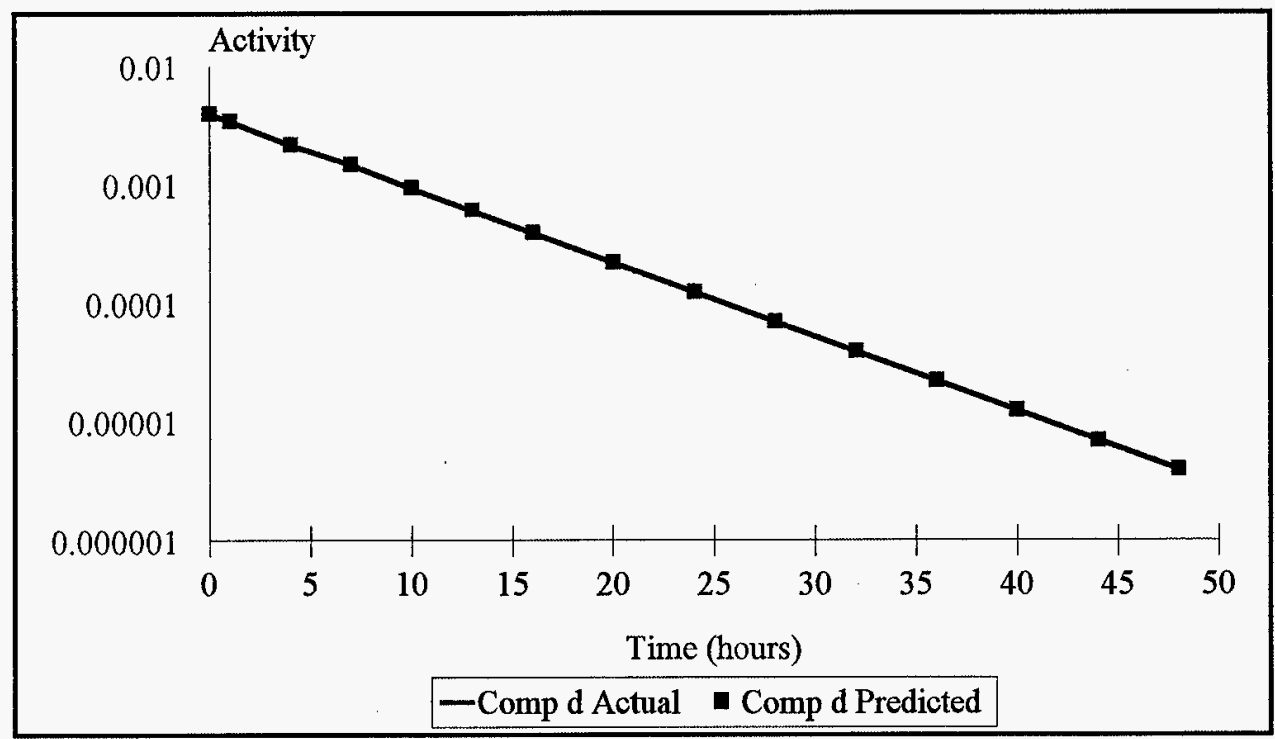

Figure 4-5. Activity as a function of time based on the analytical solution and SAAM 31 results for compartment $d$ of the lung model. 


\section{Chapter V}

Iodine Kinetics and Absorbed Dose Estimates for Athyroid Individuals

Radioiodine plays an important role in the treatment of thyroid cancer. Surgery is often used to remove the tumor and surrounding tissue, or to resect the entire thyroid gland. Although surgery is the most common method used to treat thyroid cancer, it is not always 100 percent successful in removing all the cancerous tissue (Wagner 1988). This may be due to remnant tissue left attached to the trachea or surrounding structures, or part of the tumor may be in an inoperable location. In any case, radioiodine is often used as a therapeutic measure to destroy the remaining unwanted tissue.

Numerous studies and extensive research have established the distribution and retention of $\mathrm{NaI}$ throughout the body. It is one of the few radiopharmaceuticals for which detailed information is available concerning the in vivo distribution and retention. Berman and colleagues have described the kinetics of iodine using various compartmental models (Berman et al. 1968). Figure 5-1 shows their proposed schematic diagram for the kinetic system. The model shows three processes occurring within the thyroid gland, with a fraction of material being released to the two hormones, $T_{3}$ and $T_{4}$, and a separate compartment representing urinary excretion. The exchange of material between the compartments is indicated by the arrows.

MIRD Dose Estimate Report No. 5 (Berman et al. 1975) gives estimated absorbed doses to various tissues and organs for adults with normal thyroid function. To date, there does not appear 


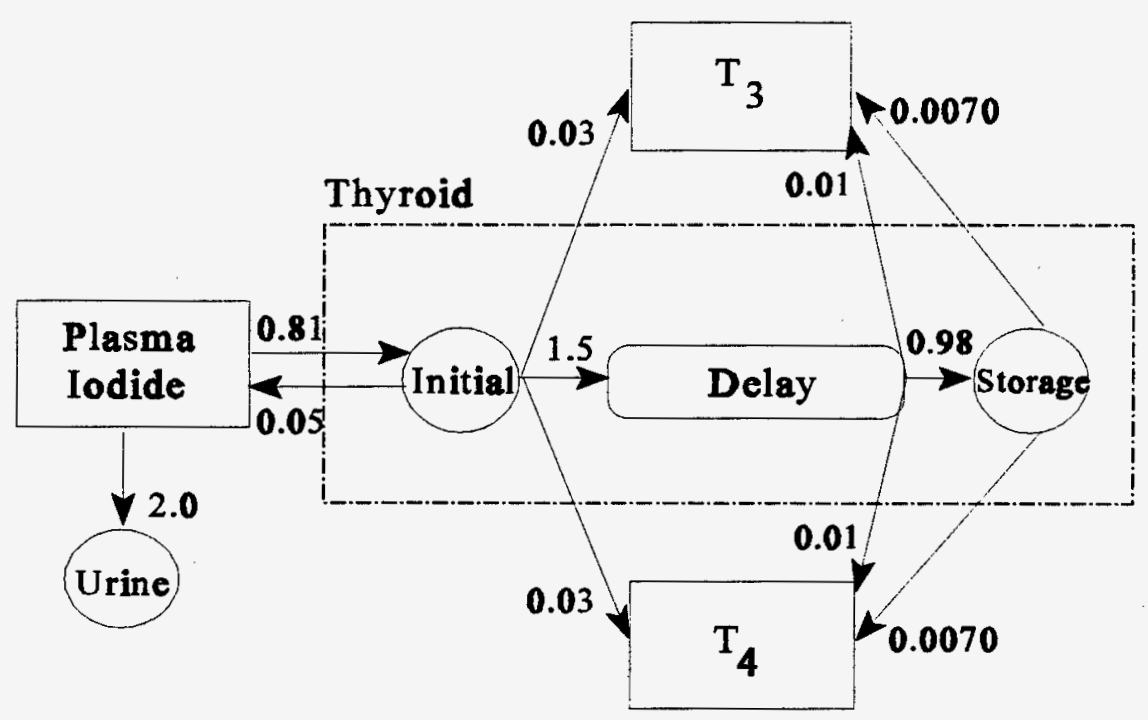

Figure 5-1. Basic model describing the kinetics of iodine. Transfer rate coefficients are given in units of day ${ }^{-1}$

to be a kinetic model or estimated absorbed doses for individuals who have had their thyroids surgically removed (athyroid) due to thyroid cancer, and treated with NaI. This chapter will address this issue through the development of a kinetic model for athyroid adult individuals, estimate of absorbed doses to various target organs based on this kinetic model, and determination of the uncertainty associated with the doses.

\section{A. Physical Data}

The mode of decay of ${ }^{131} I$ is by beta (minus) emission. The physical half-life is 8.04 days, with a physical decay constant of $0.00359 /$ hour. The photon energies, frequency emitted per 
nuclear transition, and mean energy emitted per nuclear transition are listed in Table 5-1. The photons with a frequency less than 0.01 are excluded.

Table 5-1. Physical characteristics of ${ }^{131} \mathrm{I}$.

\begin{tabular}{|c|c|c|}
\hline Energy $(\mathrm{keV})_{1}$ & $\begin{array}{c}\text { Frequency per } \\
\text { disintegration }{ }_{2}\end{array}$ & $\begin{array}{c}\Delta_{\mathrm{i} 3} \\
(\mathrm{rad} \mathrm{g} / \mu \mathrm{Ci} \mathrm{h})\end{array}$ \\
\hline 30 & 0.046 & 0.0029 \\
\hline 80 & 0.026 & 0.0044 \\
\hline 284 & 0.058 & 0.0351 \\
\hline 365 & 0.82 & 0.636 \\
\hline 637 & 0.065 & 0.0882 \\
\hline 723 & 0.017 & 0.017 \\
\hline
\end{tabular}

The mean energy per particle or photon.

${ }_{2}$ The mean number of particles or photons per nuclear transition

${ }_{3}$ The mean energy emitted per nuclear transition

\section{B. Patient Data}

Urinary excretion measurements were obtained from three athyroid patients (Tables 5-2, 5-3, and 5-4). Patient 1, a female, was administered $100 \mathrm{mCi}$ of NaI on 1/17/90, patients 2 and 3 are the same male individual, who was administered a therapeutic dose of $150 \mathrm{mCi}$ of $\mathrm{NaI}$ on $1 / 17 / 90$, and a diagnostic dose of $4 \mathrm{mCi}$ on $1 / 19 / 91$. Urine samples from patient 1 were collected from 2 to 72 days post intake. The urine volumes were normalized using the standard excretion rate of $1000 \mathrm{ml} /$ day for reference adult woman (ICRP 1975). The measured activity in the urine was converted to a percentage of the administered activity (100 mCi) (Table 5-2). Urine samples from patient 2 were collected from 3 to 55 days post intake. The standard excretion rate of 1400 $\mathrm{ml} /$ day was used for reference adult man (ICRP 1975). Urine samples from patient 3 were 
collected over a period of 37 days following treatment, and again the excretion rate assumed to be $1400 \mathrm{ml} /$ day. A percentage of the administered activity for patient 2 and 3 are listed in Tables

\section{5-3 and 5-4.}

Table 5-2. Urinary excretion data for patient 1 . Therapeutic dose of $100 \mathrm{mCi}$ delivered on $1 / 17 / 90$.

\begin{tabular}{|c|c|c|c|}
\hline $\begin{array}{l}\text { Days Post } \\
\text { Intake }\end{array}$ & $\begin{array}{l}\text { Urine Volume } \\
\text { (ml) }\end{array}$ & Activity $(\mu \mathrm{Ci})$ & $\begin{array}{c}\% \text { of Administered } \\
\text { Activity }\end{array}$ \\
\hline 2 & 430 & $1.53 \mathrm{E}+02$ & $7.1 \mathrm{E}+00$ \\
\hline 3 & 420 & $3.52 \mathrm{E}+01$ & $1.7 \mathrm{E}+00$ \\
\hline 7 & 520 & $5.86 \mathrm{E}+00$ & $1.1 \mathrm{E}-02$ \\
\hline 7 & 460 & $5.41 \mathrm{E}-01$ & $2.4 \mathrm{E}-02$ \\
\hline 9 & 200 & $1.62 \mathrm{E}+00$ & 8.1E-03 \\
\hline 9 & 100 & $1.76 \mathrm{E}-01$ & 3.5E-02 \\
\hline 12 & 340 & $5.00 \mathrm{E}-01$ & $1.5 \mathrm{E}-03$ \\
\hline 13 & 260 & $6.40 \mathrm{E}-01$ & $2.5 \mathrm{E}-03$ \\
\hline 14 & 300 & $6.35 \mathrm{E}-01$ & $2.1 \mathrm{E}-03$ \\
\hline 15 & 200 & 4.44E-01 & $2.2 \mathrm{E}-03$ \\
\hline 15 & 320 & $2.00 \mathrm{E}-02$ & $1.2 \mathrm{E}-03$ \\
\hline 17 & 225 & $2.01 \mathrm{E}-02$ & $1.8 \mathrm{E}-03$ \\
\hline 19 & 150 & $7.52 \mathrm{E}-02$ & $5.0 \mathrm{E}-04$ \\
\hline 20 & 130 & $4.27 \mathrm{E}-02$ & 3.3E-04 \\
\hline 20 & 500 & $6.53 \mathrm{E}-03$ & $2.6 \mathrm{E}-04$ \\
\hline 21 & 400 & $8.11 \mathrm{E}-02$ & $2.0 \mathrm{E}-04$ \\
\hline 22 & 420 & $6.98 \mathrm{E}-02$ & $1.7 \mathrm{E}-04$ \\
\hline 22 & 410 & $5.77 \mathrm{E}-03$ & $2.8 \mathrm{E}-04$ \\
\hline 23 & 500 & $5.81 \mathrm{E}-02$ & $1.2 \mathrm{E}-04$ \\
\hline 26 & 280 & $4.41 \mathrm{E}-02$ & $1.6 \mathrm{E}-04$ \\
\hline 28 & 380 & $1.30 \mathrm{E}-02$ & $3.4 \mathrm{E}-05$ \\
\hline 30 & 580 & $2.45 \mathrm{E}-02$ & $4.2 \mathrm{E}-05$ \\
\hline
\end{tabular}




\begin{tabular}{|c|c|c|c|}
\hline $\begin{array}{c}\text { Days Post } \\
\text { Intake }\end{array}$ & $\begin{array}{c}\text { Urine Volume } \\
(\mathrm{ml})\end{array}$ & Activity $(\mu \mathrm{Ci})$ & $\begin{array}{c}\text { \% of Administered } \\
\text { Activity }\end{array}$ \\
\hline 34 & 200 & $7.03 \mathrm{E}-03$ & $3.5 \mathrm{E}-05$ \\
\hline 35 & 520 & $8.87 \mathrm{E}-03$ & $1.7 \mathrm{E}-05$ \\
\hline 36 & 100 & $8.15 \mathrm{E}-03$ & $8.2 \mathrm{E}-05$ \\
\hline 37 & 380 & $1.17 \mathrm{E}-02$ & $3.1 \mathrm{E}-05$ \\
\hline 40 & 80 & $4.64 \mathrm{E}-03$ & $5.8 \mathrm{E}-05$ \\
\hline 41 & 360 & $3.68 \mathrm{E}-03$ & $1.0 \mathrm{E}-05$ \\
\hline 47 & 130 & $3.81 \mathrm{E}-04$ & $2.9 \mathrm{E}-06$ \\
\hline 48 & 180 & $1.23 \mathrm{E}-03$ & $6.8 \mathrm{E}-06$ \\
\hline 49 & 520 & $2.45 \mathrm{E}-03$ & $4.7 \mathrm{E}-06$ \\
\hline 51 & 500 & $8.96 \mathrm{E}-04$ & $1.6 \mathrm{E}-06$ \\
\hline 56 & 520 & $9.46 \mathrm{E}-04$ & $1.8 \mathrm{E}-06$ \\
\hline 58 & 420 & $3.11 \mathrm{E}-04$ & $7.4 \mathrm{E}-07$ \\
\hline 68 & 460 & $1.92 \mathrm{E}-04$ & $4.2 \mathrm{E}-07$ \\
\hline 72 & 440 & $5.18 \mathrm{E}-05$ & $1.2 \mathrm{E}-07$ \\
\hline & & & \\
\hline
\end{tabular}

Table 5-3. Urinary excretion data for patient 2. Therapeutic dose of $150 \mathrm{mCi}$ delivered on 1/17/90.

\begin{tabular}{|c|c|c|}
\hline $\begin{array}{c}\text { Days Post } \\
\text { Intake }\end{array}$ & Activity $(\mu \mathrm{Ci})$ & $\begin{array}{c}\text { \% of Administered } \\
\text { Activity }\end{array}$ \\
\hline 3 & $3.45 \mathrm{E}+03$ & $2.3 \mathrm{E}+00$ \\
\hline 4 & $8.38 \mathrm{E}+02$ & $5.6 \mathrm{E}-01$ \\
\hline 5 & $1.61 \mathrm{E}+02$ & $1.1 \mathrm{E}-01$ \\
\hline 6 & $4.33 \mathrm{E}+01$ & $2.9 \mathrm{E}-02$ \\
\hline 7 & $1.29 \mathrm{E}+01$ & $8.6 \mathrm{E}-03$ \\
\hline 8 & $1.75 \mathrm{E}+01$ & $1.2 \mathrm{E}-02$ \\
\hline 9 & $8.12 \mathrm{E}+00$ & $5.4 \mathrm{E}-03$ \\
\hline 10 & $3.28 \mathrm{E}+00$ & $2.2 \mathrm{E}-03$ \\
\hline 11 & $6.68 \mathrm{E}+00$ & $4.5 \mathrm{E}-03$ \\
\hline
\end{tabular}




\begin{tabular}{|c|c|c|}
\hline $\begin{array}{c}\text { Days Post } \\
\text { Intake }\end{array}$ & Activity $(\mu \mathrm{Ci})$ & $\begin{array}{c}\text { \% of Administered } \\
\text { Activity }\end{array}$ \\
\hline 12 & $1.30 \mathrm{E}+00$ & $8.7 \mathrm{E}-04$ \\
\hline 13 & $2.44 \mathrm{E}+00$ & $1.6 \mathrm{E}-03$ \\
\hline 14 & $3.29 \mathrm{E}+00$ & $2.2 \mathrm{E}-03$ \\
\hline 16 & $1.37 \mathrm{E}+00$ & $9.1 \mathrm{E}-04$ \\
\hline 19 & $1.24 \mathrm{E}+00$ & $8.3 \mathrm{E}-04$ \\
\hline 21 & $1.16 \mathrm{E}+00$ & $7.8 \mathrm{E}-04$ \\
\hline 23 & $7.81 \mathrm{E}-01$ & $5.2 \mathrm{E}-04$ \\
\hline 27 & $4.98 \mathrm{E}-01$ & $3.3 \mathrm{E}-04$ \\
\hline 30 & $4.19 \mathrm{E}-01$ & $2.8 \mathrm{E}-04$ \\
\hline 55 & $1.31 \mathrm{E}-02$ & $8.7 \mathrm{E}-06$ \\
\hline
\end{tabular}

Table 5-4. Urinary excretion data for patient 3. Diagnostic dose of $4 \mathrm{mCi}$ delivered on 1/14/91.

\begin{tabular}{|c|c|c|}
\hline $\begin{array}{l}\text { Days Post } \\
\text { Intake }\end{array}$ & Activity $(\mu \mathrm{Ci})$ & $\begin{array}{c}\% \text { of Administered } \\
\text { Activity }\end{array}$ \\
\hline 1 & $2.48 \mathrm{E}+03$ & 8.7E+01 \\
\hline 2 & $4.40 \mathrm{E}+02$ & $1.1 \mathrm{E}+01$ \\
\hline 3 & $6.26 \mathrm{E}+01$ & $1.6 \mathrm{E}+00$ \\
\hline 4 & $1.81 \mathrm{E}+01$ & $4.5 \mathrm{E}-01$ \\
\hline 5 & $3.12 \mathrm{E}+00$ & $7.8 \mathrm{E}-02$ \\
\hline 6 & $6.71 \mathrm{E}-01$ & $1.7 \mathrm{E}-02$ \\
\hline 7 & 4.61E-01 & $1.2 \mathrm{E}-02$ \\
\hline 8 & $2.84 \mathrm{E}-01$ & 7.1E-03 \\
\hline 10 & $2.00 \mathrm{E}-01$ & $5.0 \mathrm{E}-03$ \\
\hline 11 & $4.20 \mathrm{E}-02$ & $1.1 \mathrm{E}-03$ \\
\hline 12 & $2.60 \mathrm{E}-01$ & $6.5 \mathrm{E}-03$ \\
\hline 13 & $1.16 \mathrm{E}-01$ & $2.9 \mathrm{E}-03$ \\
\hline 14 & $7.47 \mathrm{E}-02$ & $1.9 \mathrm{E}-03$ \\
\hline 15 & $6.34 \mathrm{E}-02$ & $1.6 \mathrm{E}-03$ \\
\hline 16 & 4.19E-02 & $1.1 \mathrm{E}-03$ \\
\hline
\end{tabular}




\begin{tabular}{|c|c|c|}
\hline $\begin{array}{c}\text { Days Post } \\
\text { Intake }\end{array}$ & Activity $(\mu \mathrm{Ci})$ & $\begin{array}{c}\text { \% of Administered } \\
\text { Activity }\end{array}$ \\
\hline 17 & $7.39 \mathrm{E}-02$ & $1.9 \mathrm{E}-03$ \\
\hline 18 & $4.95 \mathrm{E}-02$ & $1.2 \mathrm{E}-03$ \\
\hline 19 & $4.62 \mathrm{E}-02$ & $1.2 \mathrm{E}-03$ \\
\hline 21 & $1.76 \mathrm{E}-02$ & $4.4 \mathrm{E}-04$ \\
\hline 24 & $2.21 \mathrm{E}-02$ & $5.5 \mathrm{E}-04$ \\
\hline 25 & $1.67 \mathrm{E}-02$ & $4.2 \mathrm{E}-04$ \\
\hline 26 & $1.46 \mathrm{E}-02$ & $3.7 \mathrm{E}-04$ \\
\hline 28 & $1.43 \mathrm{E}-02$ & $3.6 \mathrm{E}-04$ \\
\hline 37 & $3.33 \mathrm{E}-03$ & $8.3 \mathrm{E}-05$ \\
\hline
\end{tabular}

\section{Athyroid Model}

The percent of administered activity for each patient was fit to a 4 compartment model using the SAAM computer code (Figure 5-2). The model contains a plasma compartment with a fraction of material going directly to a compartment designated as cumulative urine. A fraction of the activity is exchanged between plasma and compartments 2 and 3 . Little information is known about these two compartments and for now are labelled as extracellular fluid (ECF) and other tissues, and may possibly represent iodine trapping in the stomach, intestines, salivary glands, etc.

The initial conditions set for the system assumes instantaneous uptake with 100 percent of the activity in the blood (plasma) at $t=0$. The initial parameter values were chosen and set closely to match the parameters given in Figure 5-1. Radioactive decay is not shown in Figure $5-2$, but is included in the solution. 


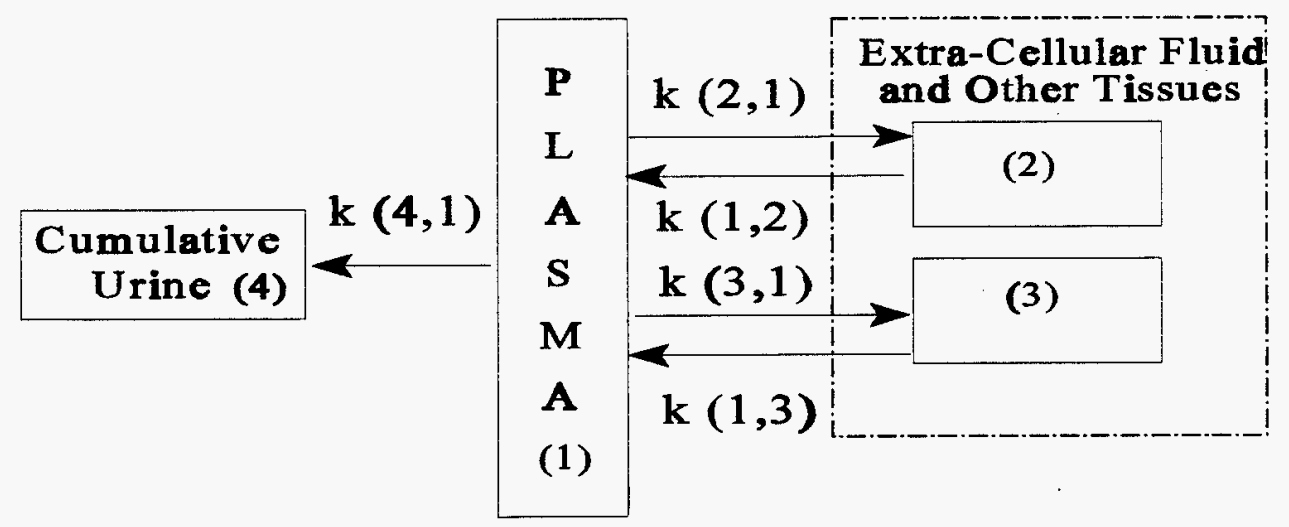

Figure 5-2. Compartmental model describing the kinetics of $\mathrm{NaI}$ $f$ or athyroid adult individuals.

Figures 5-3, 5-4, and 5-5 display graphical representations of the fitted data as a function of time generated by SAAM. For patients 1,2 , and 3, the predicted activity appears to fit reasonably well with the observed (measured) activity. However, as mentioned in the previous chapter, the accuracy of a model's predictions should not be based on visual inspection alone, thus, further investigation will be conducted. Table 5-5 gives the estimated transfer rate coefficients predicted by SAAM. The transfer rate coefficients are similar to what is predicted in MIRD Dose Report No. 5 (Berman et al. 1975).

The excretion curves are characterized by two clearance phases from the body. The first phase shows most of the material leaving the body at a rapid rate via excreta, with a mean biological half-time of 9.4 hours. The second clearance phase is represented by a slower component, which implies a fraction of the activity is bound within the body, and remains there 
over a period of time. The mean biological half-time for the long component was computed to be 5 days. The residence times for each compartment predicted by SAAM are given in Table 5-6. Whole-body residence times were determined by adding the values for plasma, ECF, and other tissues. The values were verified based on the numerical solution obtained from the computer program DIFSOLL (see Appendix B). Table 5-7 shows the percentage difference between the whole-body residence times predicted by SAAM and the observed values from the numerical solution. The difference appears to small and can be considered insignificant. The residence times for each compartment will be used to estimate the absorbed dose to various target and source regions.

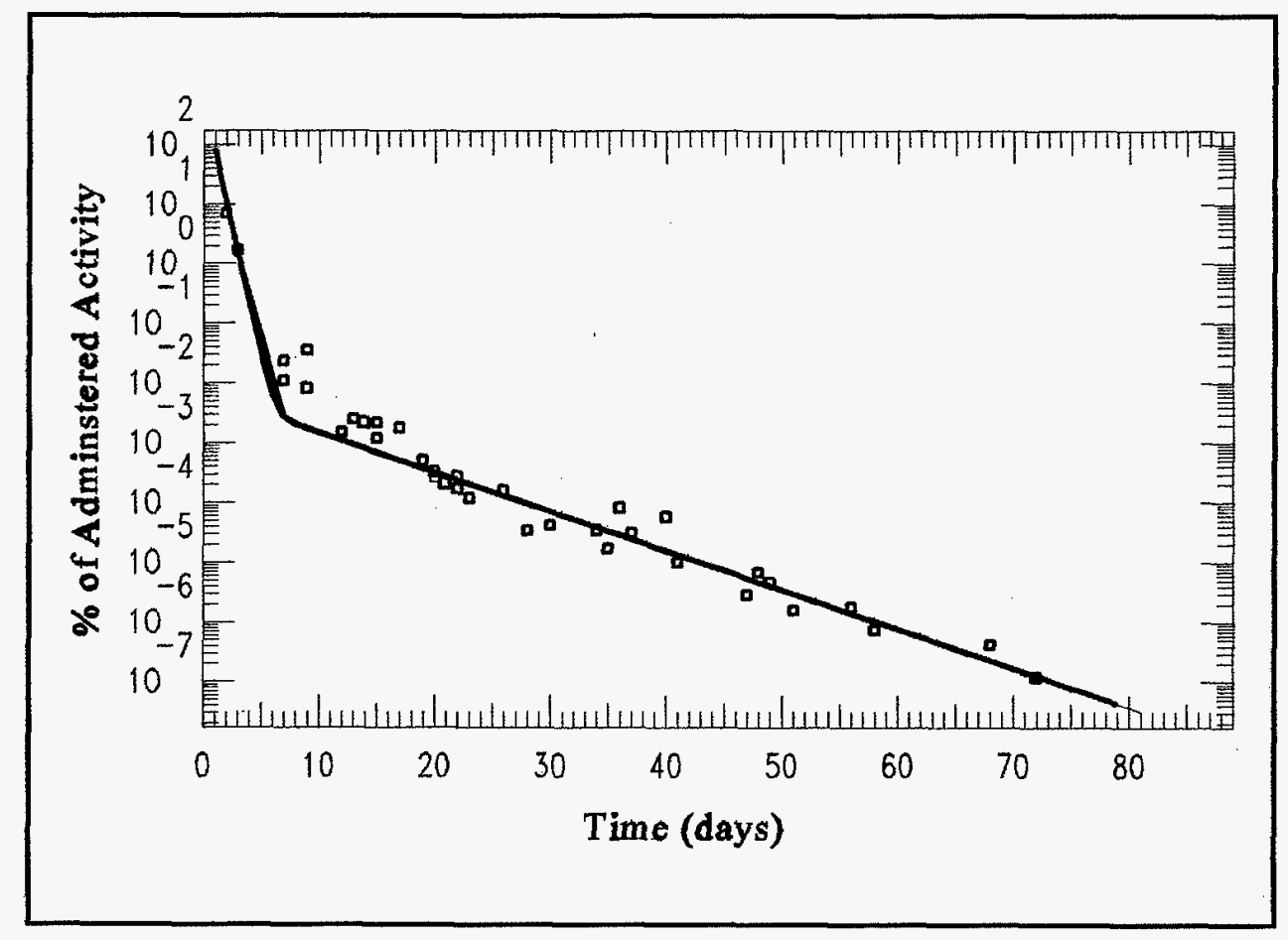

Figure 5-3. Patient 1, percent of administered activity as a function of time based on curve fitting results using the SAAM software. 


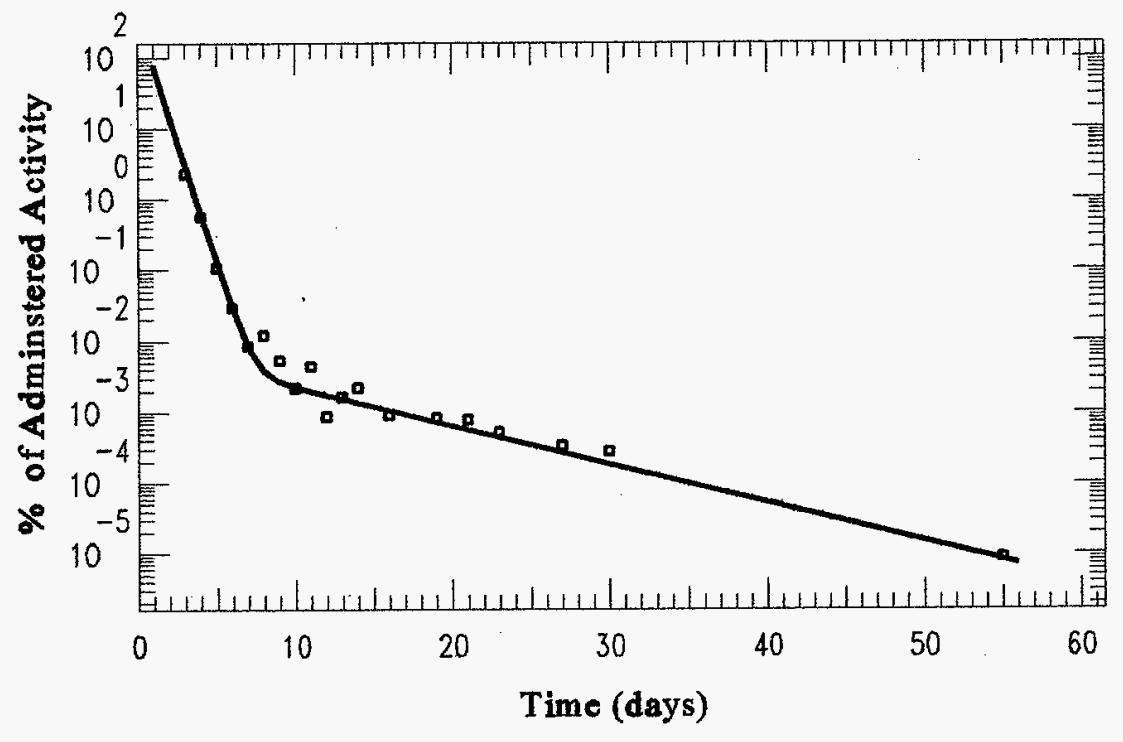

Figure 5-4. Patient 2, percent of administered activity as a function of time based on curve fitting results using the SAAM software.

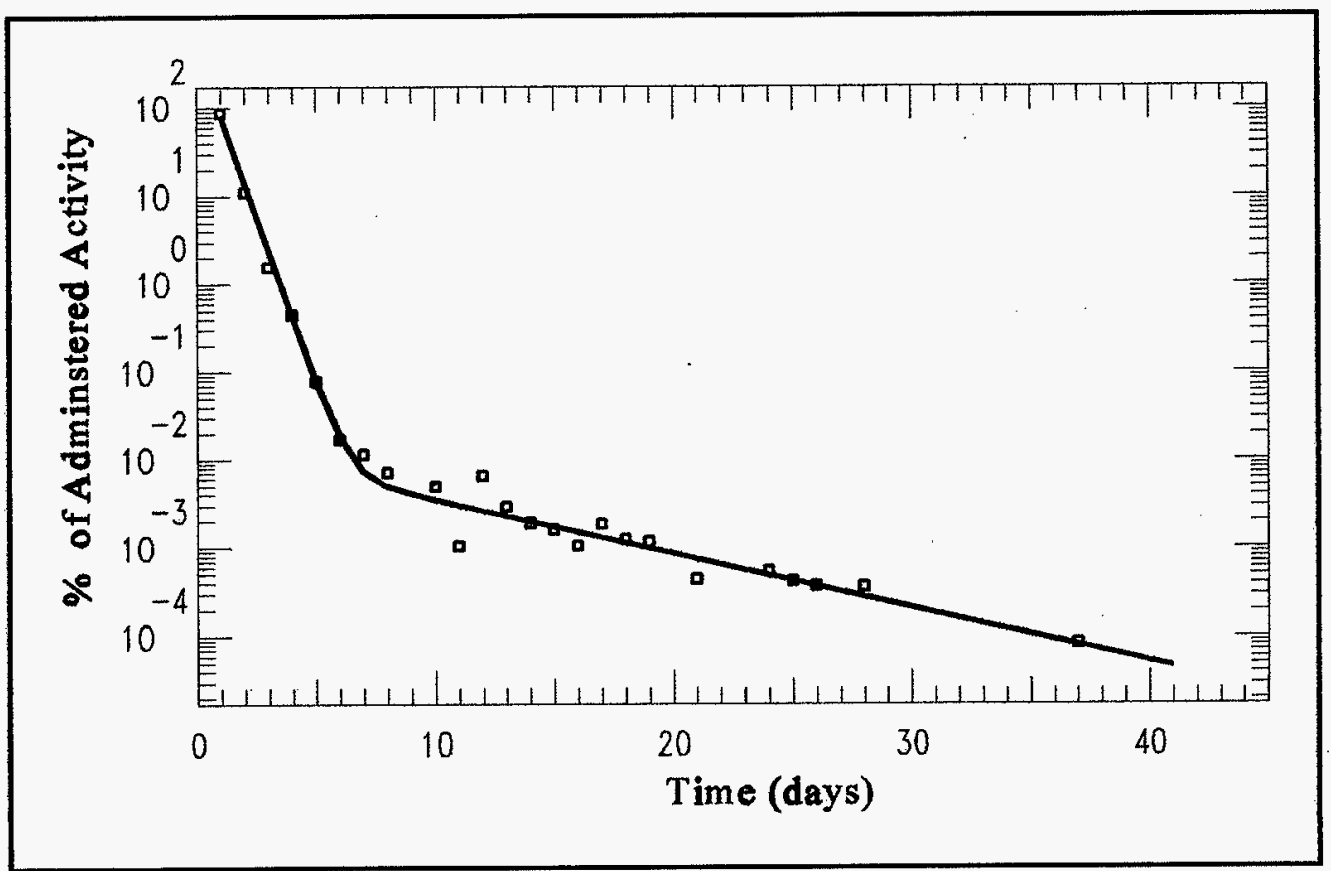

Figure 5-5. Patient 3, percent of administered activity as a function of time based on curve fitting results using the SAAM software. 
Table 5-5. Estimated transfer rate coefficients predicted by SAAM.

\begin{tabular}{|c|c|c|c|}
\hline $\begin{array}{c}\text { Transfer Rate } \\
\text { Coefficients }\end{array}$ & $\begin{array}{c}\text { Patient 1 } \\
\left(\text { days }^{-1}\right)\end{array}$ & $\begin{array}{c}\text { Patient 2 } \\
\left(\text { days }^{-1}\right)\end{array}$ & $\begin{array}{c}\text { Patient 3 } \\
\left(\text { days }^{-1}\right)\end{array}$ \\
\hline$k(1,2)$ & 0.15 & 0.125 & 0.14 \\
\hline$k(2,1)$ & 0.0007 & 0.0008 & 0.0014 \\
\hline$k(1,3)$ & 0 & 0 & 0 \\
\hline$k(3,1)$ & 0.003 & 0.001 & 0.003 \\
\hline$k(4,1)$ & 1.99 & 1.6 & 1.75 \\
\hline
\end{tabular}

Table 5-6. Residence times generated by SAAM.

\begin{tabular}{|c|c|c|c|}
\hline & \multicolumn{3}{|c|}{ Residence Times (hours) } \\
\hline Compartment & Patient 1 & Patient 2 & Patient 3 \\
\hline 1 & 11.5 & 14.2 & 13.0 \\
\hline 2 & 0.03 & 0.05 & 0.08 \\
\hline 3 & 0.40 & 0.51 & 0.46 \\
\hline 4 & 14.9 & 14.1 & 14.4 \\
\hline *Whole Body & 11.9 & 14.8 & 13.5 \\
\hline
\end{tabular}

*Compartments $1+2+3=$ Whole-body residence time

Table 5-7. Percent difference in residence times predicted by SAAM versus the observed values from the numerical solution.

\begin{tabular}{|c|c|c|c|}
\hline Patient No. & SAAM (hours) & $\begin{array}{c}\text { Numerical } \\
\text { Solution (hours) }\end{array}$ & Difference (\%) \\
\hline 1 & 11.9 & 12.1 & 1.6 \\
\hline 2 & 14.8 & 14.8 & 0.0 \\
\hline 3 & 13.5 & 13.7 & 1.5 \\
\hline
\end{tabular}


Figures 5-6 and 5-7 shows the percent of activity in the urine for a series of 24-hour periods. Figure 5-6 shows results from 0 to 80 days, and Figure 5-7 gives results from 0 to 40 days. The excretion curves for the three patients appear to be in good agreement with one another.

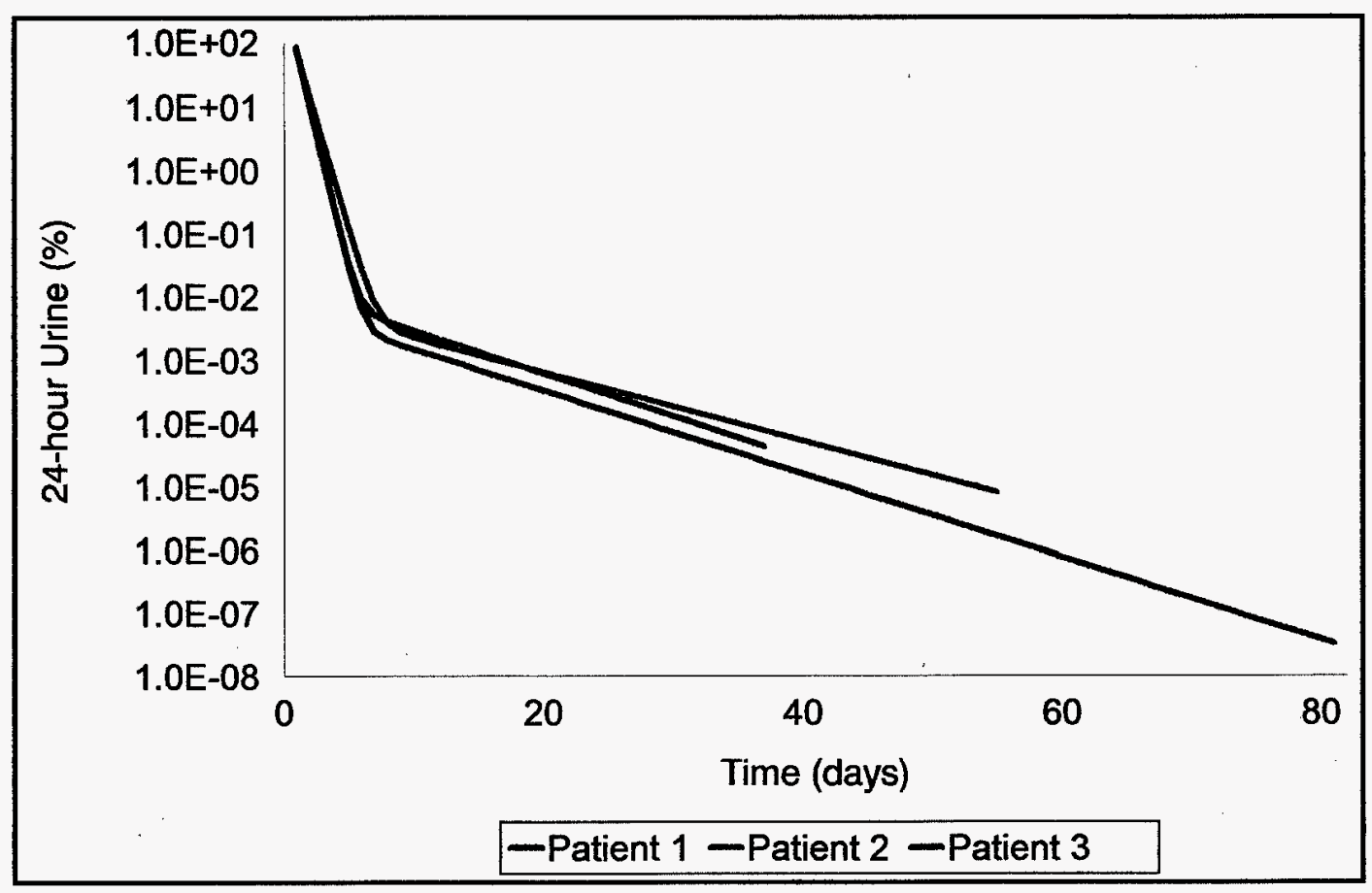

Figure 5-6. Percent of activity in 24-hour excretion period as a function of time (0 to 80 days). 


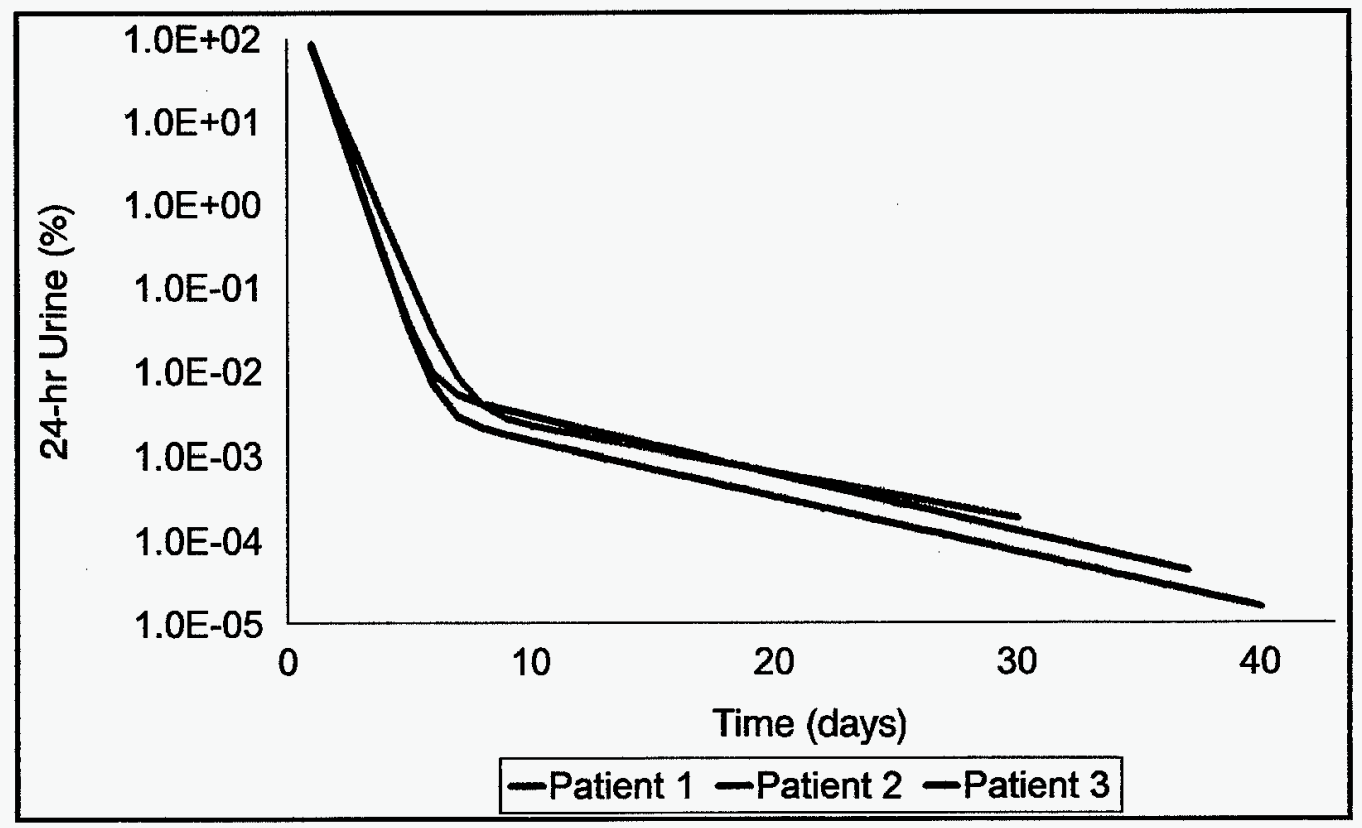

Figure 5-7. Percent of activity in 24 -hour excretion period as a function of time (0-40 days).

Urinary excretion activity was collected from 5 athyroid patients treated with NaI (patients 4-8) during a 24 and 48 hour time period (Table 5-8) (Buijs, unpublished data). An analysis using the SAAM software was not possible with this data, as only two measurements were available, and as the measurements were taken at 24 and 48 hours, only the initial fast component would be observed. Figure 5-8 is a plot of 24-hour excretion from 0 to 3 days for patients 1-3. The data for patients 4-8 were plotted on the same graph as the points. The data from all patients appear to be in relatively good agreement. 
Table 5-8. Percent of activity in urine at 24 and 48 hours.

\begin{tabular}{|c|c|c|}
\hline & \multicolumn{2}{|c|}{ \% of Activity Excreted in Urine } \\
\hline Patient No. & 24 hours & 48 hours \\
\hline 4 & 86.6 & 13 \\
\hline 5 & 80.8 & 15.4 \\
\hline 6 & 72.4 & 17.7 \\
\hline 7 & 69.9 & 17.1 \\
\hline 8 & 80.7 & 11.2 \\
\hline
\end{tabular}

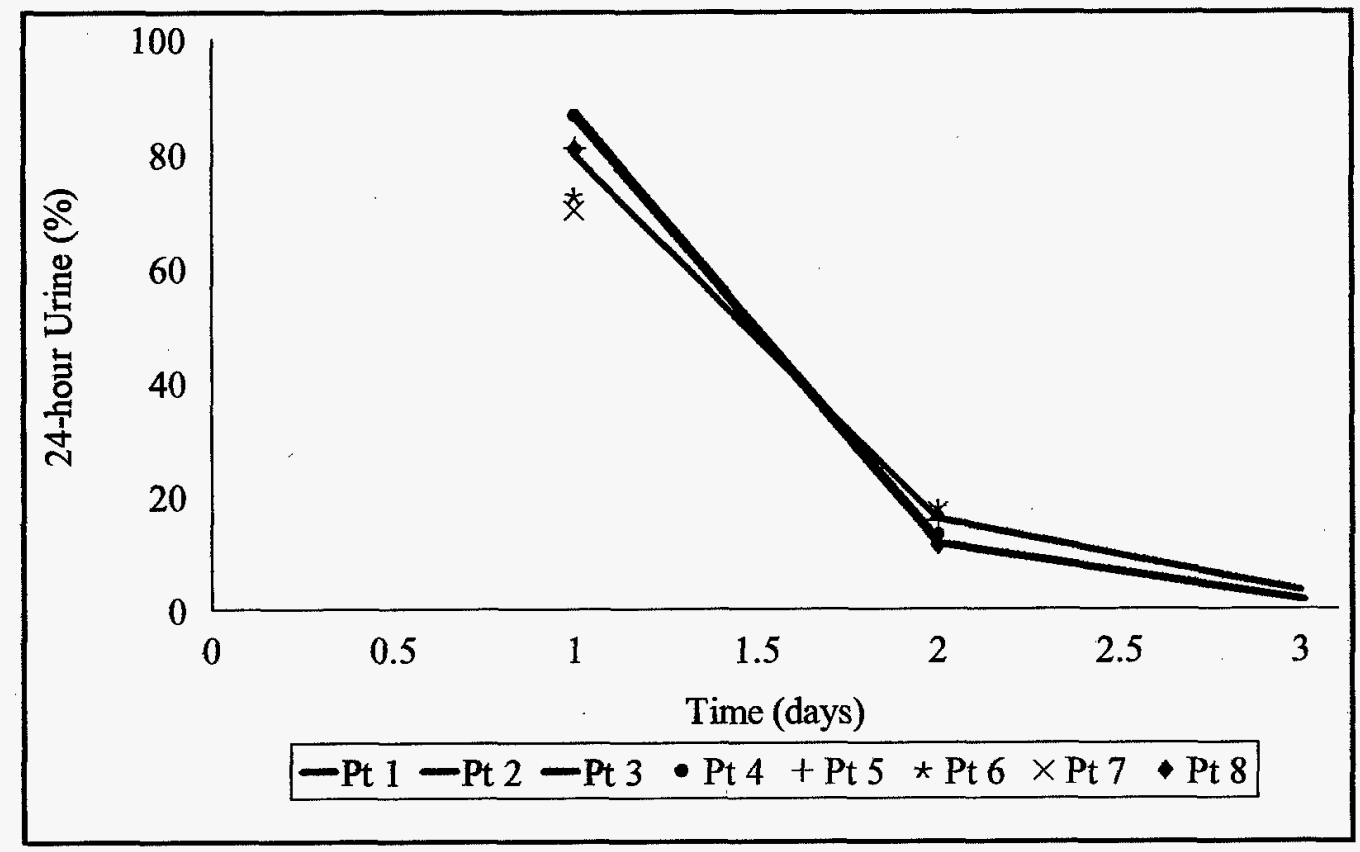

Figure 5-8. 24-hour excretion (\%) as a function of time for patients 1-3 (lines) and patients 4-8 (points).

Edmonds et al. (1970), discuss the retention of iodine within the body for subjects with no remnant thyroid tissue. Edmonds et al. (1970) observed two components of retention. The first 
being a fast initial component, with a biological half-life of 11 to 15 hours, and a second slower component with a half-life ranging from 14 to 20 days. Edmonds and colleagues state the first component reveals a fast excretion rate of iodine, and the slower component, being 0.1 to 0.2 percent of the administered dose, and is presumed to be organic binding of iodine taking place elsewhere in the body.

Figure 5-9 is a graphical representation of whole-body retention from 1 to 7 days for patients 1-3 with the results from Edmond's observations. Whole-body radioiodine retention for 14 athyroid patients was plotted as points at 2 and 7 days (Table 5-9) (Buijs, unpublished data). The implementation of SAAM was not possible with this data for reasons previously mentioned.

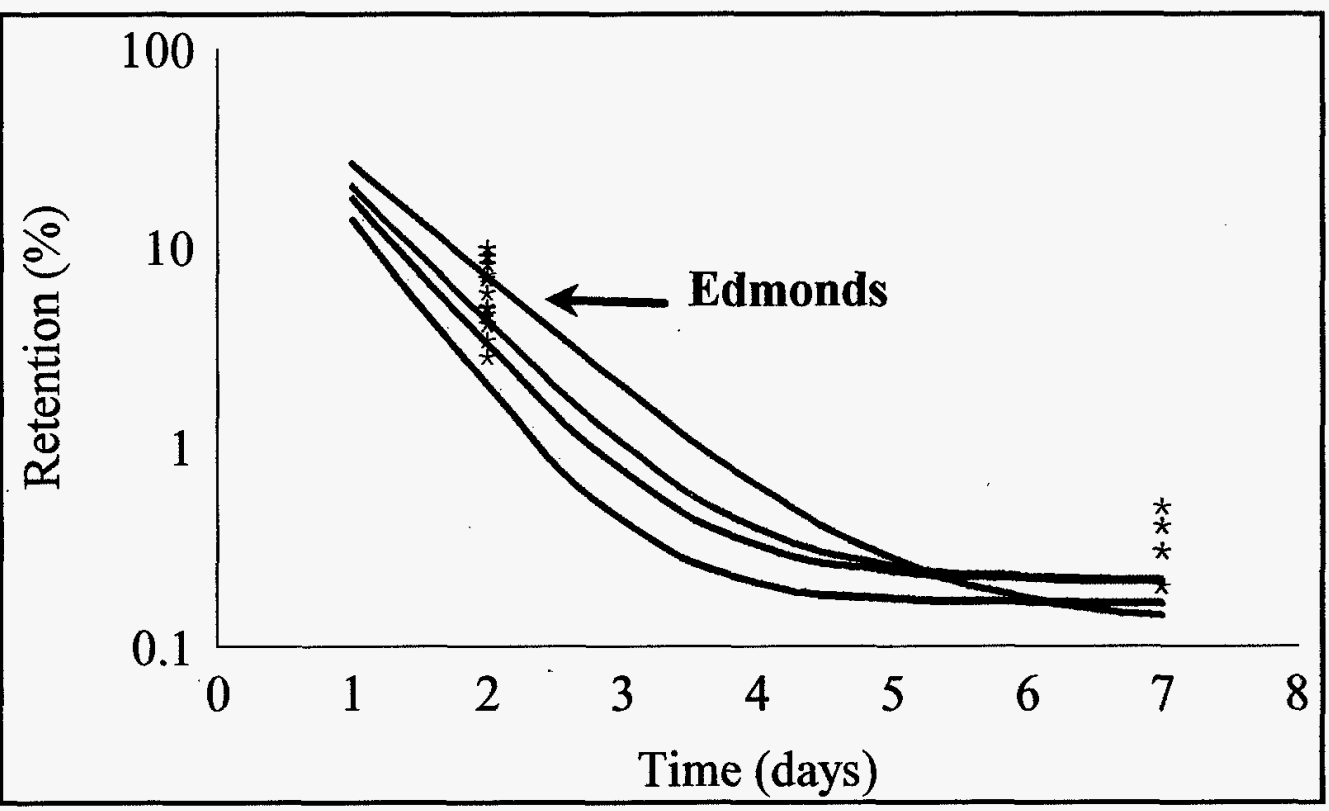

Figure 5-9. Whole-body radioiodine retention curves from 1-7 days and plotted points at 2 and 7 days. 
Table 5-9. Percent of whole-body radioiodine retention for athyroid patients.

\begin{tabular}{|c|c|}
\hline \% Retention at 2 days & \% Retention at 7 days \\
\hline 3.4 & 0.2 \\
\hline 5.9 & 0.3 \\
\hline 4.9 & 0.2 \\
\hline 9.9 & 0.4 \\
\hline 4.6 & 0.3 \\
\hline 9.1 & 0.3 \\
\hline 9.0 & 0.3 \\
\hline 5.0 & 0.2 \\
\hline 8.3 & 0.5 \\
\hline 7.3 & 0.2 \\
\hline 4.1 & 0.2 \\
\hline 7.0 & 0.3 \\
\hline 1.0 & 0.4 \\
\hline 2.8 & 0.2 \\
\hline
\end{tabular}

D. Estimated Absorbed Dose

\section{MIRDOSE}

Although SAAM allows the user to obtain the residence times, it is beyond the program's function to estimate the absorbed dose for the site of interest. MIRDOSE is a computer software program used specifically in estimating the radiation dose. The program uses various anatomic models and the dose can be determined for adult males, adult females, pregnant females at various stages of pregnancy, 15-year olds, 10-year olds, 5-year olds, 1-year olds and newborns. 
MIRDOSE (Version 3) allows the user to choose among 223 radionuclides and includes a built-in library of radionuclide decay tables and specific absorbed fractions which are used to determine the S-value(s) (Stabin 1996). The only input required by the program is the residence time(s). The program automatically calculates the radiation dose to 26 target organs and provides the effective dose equivalent and effective dose.

The estimated mean absorbed doses for various target regions were calculated using the MIRDOSE software (Version 3). Table 5-10 lists the dose associated with the short component and the sum of the short and long components for each patient. Recall, the dose contribution from the short component represents the removal of iodine from the body at a rapid rate with a mean biological half-live of 9.4 hours, and the dose contribution from the long component represents the amount of iodine trapped within the body and is excreted at a slower rate (mean biological half-live of 5.0 days). It appears the dose contribution from the long component has little effect, if any, on the dosimetry regarding patients 1,2 , and 3 .

Table 5-10. Estimated absorbed dose for the short and long components.

\begin{tabular}{|c||c|c||c|c||c||c||}
\hline \multicolumn{1}{|c||}{} & \multicolumn{2}{c||}{ Patient 1 } & \multicolumn{3}{c||}{ Patient 2 } & \multicolumn{2}{c||}{ Patient 3 } \\
\hline Target Organ & $\begin{array}{c}\text { Short } \\
(\mathrm{rad} / \mathrm{mCi})\end{array}$ & $\begin{array}{c}\text { Short + Long } \\
(\mathrm{rad} / \mathrm{mCi})\end{array}$ & $\begin{array}{c}\text { Short } \\
(\mathrm{rad} / \mathrm{mCi})\end{array}$ & $\begin{array}{c}\text { Short + Long } \\
(\mathrm{rad} / \mathrm{mCi})\end{array}$ & $\begin{array}{c}\text { Short } \\
(\mathrm{rad} / \mathrm{mCi})\end{array}$ & $\begin{array}{c}\text { Short + Long } \\
(\mathrm{rad} / \mathrm{mCi})\end{array}$ \\
\hline Adrenals & 0.157 & 0.163 & 0.139 & 0.145 & 0.152 & 0.158 \\
\hline Brain & 0.130 & 0.136 & 0.116 & 0.121 & 0.126 & 0.131 \\
\hline Breasts & 0.124 & 0.129 & 0.109 & 0.114 & 0.119 & 0.124 \\
\hline Gallbladder Wall & 0.161 & 0.167 & 0.147 & 0.153 & 0.159 & 0.165 \\
\hline LLI Wall & 0.22 & 0.226 & 0.189 & 0.195 & 0.201 & 0.207 \\
\hline Small Intestine & 0.175 & 0.181 & 0.161 & 0.167 & 0.173 & 0.18 \\
\hline
\end{tabular}




\begin{tabular}{|c|c|c|c|c|c|c|}
\hline \multirow[b]{2}{*}{ Target Organ } & \multicolumn{2}{|c|}{ Patient 1} & \multicolumn{2}{|c|}{ Patient 2} & \multicolumn{2}{|c|}{ Patient 3} \\
\hline & $\begin{array}{c}\text { Short } \\
(\mathrm{rad} / \mathrm{mCi})\end{array}$ & $\begin{array}{l}\text { Short + Long } \\
(\mathrm{rad} / \mathrm{mCi})\end{array}$ & $\begin{array}{c}\text { Short } \\
(\mathrm{rad} / \mathrm{mCi})\end{array}$ & $\begin{array}{l}\text { Short + Long } \\
(\mathrm{rad} / \mathrm{mCi})\end{array}$ & $\begin{array}{c}\text { Short } \\
(\mathrm{rad} / \mathrm{mCi})\end{array}$ & $\begin{array}{l}\text { Short + Long } \\
(\mathrm{rad} / \mathrm{mCi})\end{array}$ \\
\hline Stomach & 0.154 & 0.161 & 0.138 & 0.144 & 0.15 & 0.156 \\
\hline ULI Wall & 0.176 & 0.183 & 0.154 & 0.161 & 0.167 & 0.173 \\
\hline Liver & 0.151 & 0.158 & 0.134 & 0.14 & 0.146 & 0.152 \\
\hline Lungs & 0.143 & 0.149 & 0.125 & 0.13 & 0.136 & 0.141 \\
\hline Muscle & 0.151 & 0.156 & 0.134 & 0.14 & 0.145 & 0.15 \\
\hline Ovaries & 0.217 & 0.223 & 0.188 & 0.194 & 0.2 & 0.207 \\
\hline Pancreas & 0.162 & 0.168 & 0.145 & 0.151 & 0.158 & 0.164 \\
\hline Red Marrow & 0.153 & 0.159 & 0.137 & 0.142 & 0.148 & 0.154 \\
\hline Bone Surfaces & 0.163 & 0.17 & 0.147 & 0.154 & 0.16 & 0.166 \\
\hline Skin & 0.122 & 0.126 & 0.109 & 0.113 & 0.118 & 0.122 \\
\hline Spleen & 0.151 & 0.158 & 0.134 & 0.14 & 0.146 & 0.152 \\
\hline Testes & - & - & 0.155 & 0.16 & 0.165 & 0.171 \\
\hline Thymus & 0.145 & 0.151 & 0.128 & 0.134 & 0.139 & 0.145 \\
\hline Urinary Bladder Wall & 3.97 & 3.98 & 2.9 & 2.9 & 2.88 & 2.88 \\
\hline Uterus & 0.281 & 0.288 & 0.248 & 0.255 & 0.26 & 0.266 \\
\hline Total Body & 0.154 & 0.16 & 0.136 & 0.141 & 0.147 & 0.152 \\
\hline${ }^{*}$ Eff Dose Equiv & 0.407 & 0.413 & 0.322 & 0.328 & 0.332 & 0.338 \\
\hline *EffDose & 0.376 & 0.382 & 0.298 & 0.304 & 0.309 & 0.314 \\
\hline
\end{tabular}

* Units $=\mathrm{rem} / \mathrm{mCi}$

E. Uncertainty Analysis

Recall, the MIRD technique describes the mean absorbed dose to the target region as: 


$$
\bar{D}\left(r_{k} \leftarrow r_{h}\right)=A_{0} \sum_{h} \tau_{h} S\left(r_{k} \leftarrow r_{h}\right)
$$

Determining the uncertainty in the mean dose can be difficult. There are many sources that can contribute to the overall uncertainty. The uncertainty associated with the dose to the target organs that are listed in Table 5-10, is related to the variability in the parameters involved in the dose equation above. The initial activity, $\mathrm{A}_{0}$, is normally known and can be accurately measured, thus the uncertainty is within the two remaining parameters, $\tau$ and the S-value. The variability in the S-value is related to the absorbed fraction, the fraction of energy emitted by the source organ that is absorbed in the target organ, and the variability in the mass of the target organ. The uncertainty involved in the remaining parameter, $\tau$, residence time, is primarily associated with the inter-patient retention variability.

The uncertainty in the absorbed dose will be estimated by propagating the variability of the residence time(s) through the dose equation (Eq. 5-1). All other sources of uncertainty will be neglected. The reader should be aware that the sample size (three individuals) is not a large sample and does not adequately represent a true population. In order for this to be an accurate analysis additional data and research would be needed, thus this analysis serves more as an exercise in demonstrating the process of uncertainty analysis. 
The solution to a compartmental model with constant transfer rate coefficients can be described as a series of exponential terms. Equation 5-2 is the numerical solution for the model describing athyroid individuals.

$$
A(t)=\sum_{i=1}^{n} a_{i} e^{-\left(k_{i}+k_{p}\right) t}
$$

As previously mentioned, the residence time is the quotient of the cumulated activity and the administered activity. The residence time is mathematically described by equation 5-3.

$$
\tau_{w b}=\frac{\tilde{A}_{h}}{A_{0}}=\int_{0}^{\infty} \sum_{i=1}^{n} a_{i} e^{-\left(k_{i}+k_{p}\right) t} d t
$$

Solving this yields the following:

$$
\tau=\sum_{i=1}^{n} \frac{a_{i}}{\left(k_{i}+k_{p}\right)}
$$

The uncertainty in $\tau$ was computed using the analytical first order error propagation method (eq. 5-5). The equation describing the variation in $\tau$ uses the Taylor Series Expansion methodology. This expression is an approximation to the actual function because it uses only the 
first order term from the expansion method (Morgan and Henrion 1990).

$$
\operatorname{Var}[\tau] \approx \sum_{i=1}^{n} \sum_{j=1}^{n} \operatorname{Covar}\left(x_{i}, x_{j}\right)\left(\frac{\partial \tau}{\partial x_{i}}\right)_{x_{0}}\left(\frac{\partial \tau}{\partial x_{j}}\right)_{x_{0}}
$$

Table 5-11 lists the parameters $\mathrm{a}_{\mathrm{i}}$ and $\mathrm{k}_{\mathrm{i}}$ from the numerical solution of the thyroid model. The mean, standard deviation, and partial derivative of $\tau$ with respect to each parameter was calculated. The solution to the partial derivative of $\tau$ with respect to $a_{i}$ and $k_{i}$ is shown in equations 5-8 and 5-9, respectively.

The covariance in equation 5-5 describes the measure of two parameters about their means, and is expressed as:

$$
\operatorname{Covar}\left[x_{t}, x_{j}\right] \equiv E\left[\left(x_{t}-x_{t}^{0}\right)\left(x_{j}-x_{j}^{0}\right)\right]
$$

where,

$\mathrm{E}$ is the mean scenario, or the expectation of $\mathrm{X}$, and $\mathrm{X}^{0}$ is the derived calculation of the nominal value (i.e. mean):

$$
E[X]=X^{0}=\left(x_{1}^{0}, x_{2}^{0}, x_{3}^{0}, \ldots . x_{n}^{0}\right)
$$


Table 5-11. Mean, standard deviation, and the partial derivative of $\tau$ with respect to the various parameters.

\begin{tabular}{|c|l|l|l|}
\hline $\begin{array}{c}\text { Parameter } \\
\left(\mathrm{x}_{\mathrm{j}}\right)\end{array}$ & Mean & $\begin{array}{c}\text { Standard } \\
\text { Deviation }\end{array}$ & $\frac{\partial \tau}{\partial x_{i}}$ \\
\hline $\mathrm{a}_{1}$ & $9.99 \mathrm{E}-01$ & $2.55 \mathrm{E}-05$ & $5.36 \mathrm{E}-01$ \\
\hline $\mathrm{a}_{2}$ & $5.07 \mathrm{E}-05$ & $2.28 \mathrm{E}-05$ & $4.42 \mathrm{E}+00$ \\
\hline $\mathrm{a}_{3}$ & $-5.97 \mathrm{E}-04$ & $2.50 \mathrm{E}-04$ & $5.36 \mathrm{E}-01$ \\
\hline $\mathrm{a}_{4}$ & $5.97 \mathrm{E}-04$ & $2.50 \mathrm{E}-04$ & $4.42 \mathrm{E}+00$ \\
\hline $\mathrm{a}_{5}$ & $1.72 \mathrm{E}-03$ & $2.05 \mathrm{E}-04$ & $1.16 \mathrm{E}+01$ \\
\hline $\mathrm{a}_{6}$ & $-1.72 \mathrm{E}-03$ & $2.05 \mathrm{E}-04$ & $5.36 \mathrm{E}-01$ \\
\hline $\mathrm{a}_{7}$ & $-1.13 \mathrm{E}-06$ & $5.19 \mathrm{E}-07$ & $4.42 \mathrm{E}+00$ \\
\hline $\mathrm{k}_{1}$ & 1.78 & 0.19 & $2.87 \mathrm{E}-01$ \\
\hline $\mathrm{k}_{2}$ & 0.14 & 0.01 & $9.93 \mathrm{E}-04$ \\
\hline $\mathrm{k}_{3}$ & 1.78 & 0.19 & $1.71 \mathrm{E}-04$ \\
\hline $\mathrm{k}_{4}$ & 0.14 & 0.01 & $1.17 \mathrm{E}-02$ \\
\hline $\mathrm{k}_{5}$ & 0.00 & 0.00 & $2.33 \mathrm{E}-01$ \\
\hline $\mathrm{k}_{6}$ & 1.78 & 0.19 & $4.95 \mathrm{E}-04$ \\
\hline $\mathrm{k}_{7}$ & 0.14 & 0.01 & $2.21 \mathrm{E}-05$ \\
\hline
\end{tabular}

Solution to the partial derivative of $\tau$ with respect to parameter $a_{i}$ :

$$
\left(\frac{\partial \tau}{\partial a_{t}}\right)=\frac{1}{k_{t}+k_{p}}
$$


Solution to the partial derivative of $\tau$ with respect to parameter $k_{i}$ :

$$
\left(\frac{\partial \tau}{\partial k_{l}}\right)=-\left[\frac{a_{t}}{\left(k_{i}+k_{p}\right)^{2}}\right]
$$

Using the analytical first order error propagation method as described above, the variance in the residence time was estimated to equal:

$$
\operatorname{Var}[\tau]=0.0029 \text { days }^{2}
$$

From the variance, the standard deviation was determined to be 1.3 hours. The mean was previously determined to be 13.5 hours, thus if the residence time is normally distributed then the $95 \%$ confidence interval lies between 10.9 and 16.1 hours. 


\section{Chapter VI}

Conclusions

The risk to an individual undergoing any type of treatment that uses radioactive material should be minimized and always be compared to the benefits that may be obtained from the procedure. In general, this data can be used as a basis in estimating the risk to athyroid individuals undergoing radioiodine treatment.

This study describes a kinetic model and radiation dose estimates for athyroid adult individuals treated with radioactive labeled NaI. The model is used to compute the distribution and retention of $\mathrm{NaI}$ and is composed of four compartments where it includes a short and long component of retention times.

The absorbed doses calculated from the short and the sum of the short and long components revealed that the contribution from the long component was less than five percent of the total dose. The urinary bladder wall appeared to receive the largest dose, with a mean of $3.25 \mathrm{rad} / \mathrm{mCi}$ from the short component and $3.25 \mathrm{rad} / \mathrm{mCi}$ with the addition of the long component. The mean dose to the total body was determined to be $0.146 \mathrm{rad} / \mathrm{mCi}$ from the short component and $0.151 \mathrm{rad} / \mathrm{mCi}$ from the short and long components.

The model could be further improved by identifying compartments two and three which are for now labeled "extracellular fluid and other tissues." This would require extensive research and data 
analysis, and although this information would be useful to an extent, it probably is not needed for this study.

Given the small sample number, a validation analysis of the model was not performed. A validation analysis will be considered in the near future pending the collection and analysis of new data.

The uncertainty in the estimates of residence time was most likely due to inter-patient variability. The parameters describing the elimination rate of $\mathrm{NaI}$ can vary from one individual to another. Factors such as age, gender, and even height and weight, may attribute to the parameters being described as a range of values rather than a single number. Again, due to the small sample size, the uncertainty in the residence time varied considerably. 


\section{REFERENCES}

Berman, M. MIRD Pamphlet No. 12. Kinetic Models for Absorbed Dose Calculations. The Society of Nuclear Medicine; New York; 1977.

Berman, M.; Braverman, L. E.; Burke, J.; De Groot, L.; McCormack, K. R.; Oddie, T. H.; Rohrer, R. H.; Wellman, H. N.; Smith, E. M. MIRD Dose Estimate Report No. 5: I-123, I124, I-125, I-126, I-130, I-131, and I-132 as Sodium Iodide. J Nucl Med 16:857-860; 1975.

Berman, M.; Hoff, E.; Barandes, M.; Becker, D. V.; Sonenberg, M.; Benua, R.; Koutras, D. A. Iodine kinetics in man - A model. J Clin Endocrinol Metabol 28:1-14; 1968.

Berman, M.; Weiss, M. F. Users manual for SAAM (Simulation, Analysis, and Modeling). Version: SAAM 27. U. S. Department of Health, Education and Welfare, National Institute of Health, Bethesda, MD; DHEW Publication No. (NIH) 78-180; 1978.

Brown-Grant, K. Extrathyroidal iodide concentrating mechanisms. Physiological Reviews 41:190-198; 1961.

Cember, H. Introduction to health physics. 2nd ed. Elmsford, NY: Pergamon Press; 1985.

Cloutier, R. J.; Watson, E. E. Radiopharmaceutical dosimetry: An introduction to the MIRD technique. Radiopharmaceutical Internal Dosimetry; Reference Manual. Radiation Internal Dose Information, Oak Ridge, Tennessee, unpublished; 1977.

Cristy, M.; Eckerman, K. Specific absorbed fractions of energy at various ages from internal photon sources. ORNL/TM-8381 V1-V7. Oak Ridge, TN: Oak Ridge National Laboratory; 1987.

Edmonds, C. J.; Smith, T.; Barnaby, C.F. Follow-up of thyroid carcinoma by whole-body counting. Br. J. Radiol., 43:868-875; 1970.

Gurley, L. T.; Callaway, W. J. Introduction to radiologic technology. 3rd ed. St. Louis, MO: Mosby-Year Book, Inc.; 1992.

International Commission on Radiation Units and Measurements. Methods of assessment of absorbed dose in clinical use of radionuclides. Washington, D. C.: ICRU Publications; Report $32 ; 1979$.

International Commission on Radiological Protection. Report of the task group on reference man. Oxford: Pergamon Press; ICRP Publication 23; 1975. 
International Commission on Radiological Protection. Limits for intakes of radionuclides by workers. Oxford: Pergamon Press; ICRP Publication 30; 1979.

International Commission on Radiological Protection. Radiation dose to the patients from radiopharmaceuticals. Oxford: Pergamon Press; ICRP Publication 53; 1988.

Kirchner, T. B. Uncertainty analysis. Pathway analysis and risk assessment for environmental compliance and dose reconstruction. Training manual. Radiological Assessment Corporation, Kiawah Island, SC; 1994.

Loevinger, R.; Berman, M. A revised schema for calculating the absorbed dose from biologically distributed radionuclides. The Society of Nuclear Medicine; New York; 1976.

Loevinger, R.; Budinger, T. F.; Watson, E. E. MIRD primer for absorbed dose calculations. Revised edition. New York: The Society of Nuclear Medicine, Inc.; 1991.

Madu, C. N.; Kuei, C. Experimental statistical designs and analysis in simulation modeling. Westport, CT: Quorum Books; 1993.

Marieb, E. N. Human anatomy and physiology. 2nd ed. Redwood City, CA: The Benjamin/Cummings Publishing Company, Inc.; 1992.

Morgan, M. G.; Henrion, M. Uncertainty A guide to dealing with uncertainty in quantitative risk and policy analysis. New York, NY: Cambridge University Press; 1990.

National Council on Radiation Protection and Measurements. Nuclear Medicine- Factors influencing the choice and use of radionuclides in diagnosis and therapy. Bethesda, MD: NCRP; NCRP Report No. 70; 1982.

National Council on Radiation Protection and Measurements. General concepts for the dosimetry of internally deposited radionuclides. Bethesda, MD: NCRP; NCRP Report No. 84; 1985.

Pitt-Rivers, R.; Trotter, W. R. The thyroid gland. Vol 1. England: Butterworth \& Co. Ltd.; 1964.

Seeley, R. R.; Stephens, T. D.; Tate, P. Anatomy \& physiology. 3rd ed. St. Louis, MO: Mosby-Year Book, Inc.; 1995.

Snyder, W. S.; Ford, M. R.; Warner, G. G. MIRD Pamphlet No. 5. Estimates of specific absorbed fractions for photon sources uniformly distributed in various organs of a heterogeneous phantom. The Society of Nuclear Medicine; New York; 1978. 
Stabin M. G. Radiopharmaceutical internal dose calculation techniques. Radiation Internal Dose Information Center, Oak Ridge, Tennessee. Unpublished; 1993.

Stabin M. G. MIRDOSE: Personal Computer Software for Internal Dose Assessment in Nuclear Medicine. J Nucl Med 37:538-546; 1996.

Stabin M. G.; Watson, E.; Cristy, M.; et al. Mathematical models of the adult female at various stages of pregnancy. ORNL Report ORNL/TM-12907. Oak Ridge, TN: Oak Ridge National Laboratory; 1995: in press.

Wagner, H. N., Jr. Principles of nuclear medicine. Philadelphia, PA: W. B. Saunders Company; 1988.

Watson, E. E. Radiation absorbed dose to the human fetal thyroid. In: Watson, E. E.; SchlarfeStelson, A. eds. Fifth International Radiopharmaceutical Dosimetry Symposium. Oak Ridge, TN: Oak Ridge Associated Universities; CONF-910529; 1992.

Whicker, F. W.; Schultz, V. Radioecology: Nuclear energy and the environment. Vol II. Boca Raton, FL: CRC Press, Inc.; 1982.

Williams, R. H. Textbook of endocrinology. 4th ed. Philadelphia, PA: W.B. Saunders Company; 1968.

Zill, D. G. A first course in differential equations with applications. 4th ed. Boston, MA: PWSKENT Publishing Company; 1989. 


\section{APPENDIX A}

Results from the analytical solutions and predicted values generated by the SAAM software for the stomach and lower large intestine compartments from the ICRP 30 GI tract model and compartment $d$ of the lung model. A ratio of the actual and predicted values was determined to compare the results.

Table A-1. Activity as a function of time for the stomach compartment derived from the analytical solution and predicted by SAAM.

\begin{tabular}{|c|c|c|c|}
\hline Time (hours) & $\begin{array}{c}\text { ST Activity } \\
\text { (Actual) }\end{array}$ & $\begin{array}{c}\text { ST Activity } \\
\text { (Predicted) }\end{array}$ & P/A \\
\hline 0 & $1.000 \mathrm{E}+00$ & $1.000 \mathrm{E}+00$ & 1.000 \\
\hline 1 & $3.679 \mathrm{E}-01$ & $3.679 \mathrm{E}-01$ & 1.000 \\
\hline 2 & $1.353 \mathrm{E}-01$ & $1.353 \mathrm{E}-01$ & 1.000 \\
\hline 3 & $4.979 \mathrm{E}-02$ & $4.979 \mathrm{E}-02$ & 1.000 \\
\hline 4 & $1.832 \mathrm{E}-02$ & $1.832 \mathrm{E}-02$ & 1.000 \\
\hline 5 & $6.738 \mathrm{E}-03$ & $6.738 \mathrm{E}-03$ & 1.000 \\
\hline 8 & $3.354 \mathrm{E}-04$ & $3.354 \mathrm{E}-04$ & 1.000 \\
\hline 10 & $4.540 \mathrm{E}-05$ & $4.540 \mathrm{E}-05$ & 1.000 \\
\hline 15 & $3.000 \mathrm{E}-07$ & $3.000 \mathrm{E}-07$ & 1.000 \\
\hline 20 & $2.061 \mathrm{E}-09$ & $2.061 \mathrm{E}-09$ & 1.000 \\
\hline 25 & $1.389 \mathrm{E}-11$ & $1.389 \mathrm{E}-11$ & 1.000 \\
\hline
\end{tabular}


Table A-2. Activity as a function of time for the lower large intestine compartment derived from the analytical solution and predicted by SAAM.

\begin{tabular}{|c|c|c|c|}
\hline Time (hours) & $\begin{array}{l}\text { LLI Activity } \\
\text { (Actual) }\end{array}$ & $\begin{array}{l}\text { LLI Activity } \\
\text { (Predicted) }\end{array}$ & $\mathrm{P} / \mathrm{A}$ \\
\hline 1 & $2.309 \mathrm{E}-03$ & $2.311 \mathrm{E}-03$ & 1.000 \\
\hline 2 & $1.367 \mathrm{E}-02$ & $1.366 \mathrm{E}-02$ & 0.999 \\
\hline 3 & $3.489 \mathrm{E}-02$ & $3.488 \mathrm{E}-02$ & 0.999 \\
\hline 4 & $6.379 \mathrm{E}-02$ & $6.377 \mathrm{E}-02$ & 0.999 \\
\hline 5 & $9.772 \mathrm{E}-02$ & $9.767 \mathrm{E}-02$ & 0.999 \\
\hline 8 & $2.087 \mathrm{E}-01$ & $2.086 \mathrm{E}-01$ & 0.999 \\
\hline 10 & $2.774 \mathrm{E}-01$ & $2.772 \mathrm{E}-01$ & 0.999 \\
\hline 15 & $4.022 \mathrm{E}-01$ & $4.018 \mathrm{E}-01$ & 0.999 \\
\hline 20 & $4.591 \mathrm{E}-01$ & $4.586 \mathrm{E}-01$ & 0.998 \\
\hline 25 & $4.664 \mathrm{E}-01$ & $4.659 \mathrm{E}-01$ & 0.998 \\
\hline 30 & $4.435 \mathrm{E}-01$ & $4.430 \mathrm{E}-01$ & 0.998 \\
\hline 35 & 4.044E-01 & $4.039 \mathrm{E}-01$ & 0.998 \\
\hline 40 & $3.586 \mathrm{E}-01$ & $3.582 \mathrm{E}-01$ & 0.998 \\
\hline 45 & $3.118 \mathrm{E}-01$ & $3.114 \mathrm{E}-01$ & 0.998 \\
\hline 50 & 2.672E-01 & $2.669 \mathrm{E}-01$ & 0.998 \\
\hline 75 & $1.094 \mathrm{E}-01$ & $1.092 \mathrm{E}-01$ & 0.998 \\
\hline 100 & $4.080 \mathrm{E}-02$ & $4.072 \mathrm{E}-02$ & 0.998 \\
\hline 125 & $1.472 \mathrm{E}-02$ & $1.469 \mathrm{E}-02$ & 0.997 \\
\hline 150 & $5.241 \mathrm{E}-03$ & $5.229 \mathrm{E}-03$ & 0.997 \\
\hline
\end{tabular}


Table A-3. Activity as a function of time for compartment $d$ derived from the analytical solution and predicted by SAAM.

\begin{tabular}{|c|c|c|c|}
\hline Time (hours) & $\begin{array}{l}\text { Compartment d } \\
\text { (Actual) }\end{array}$ & $\begin{array}{l}\text { Compartment d } \\
\text { (Predicted) }\end{array}$ & P/A. \\
\hline 0 & $4.000 \mathrm{E}-03$ & $4.000 \mathrm{E}-03$ & 1.000 \\
\hline 1 & $3.500 \mathrm{E}-03$ & $3.500 \mathrm{E}-03$ & 1.000 \\
\hline 4 & $2.200 \mathrm{E}-03$ & $2.200 \mathrm{E}-03$ & 1.000 \\
\hline 7 & $1.500 \mathrm{E}-03$ & $1.500 \mathrm{E}-03$ & 1.000 \\
\hline 10 & $9.439 \mathrm{E}-04$ & $9.442 \mathrm{E}-04$ & 1.002 \\
\hline 13 & $6.120 \mathrm{E}-04$ & $6.133 \mathrm{E}-04$ & 1.002 \\
\hline 16 & $3.968 \mathrm{E}-04$ & $3.971 \mathrm{E}-04$ & 1.002 \\
\hline 20 & $2.227 \mathrm{E}-04$ & $2.229 \mathrm{E}-04$ & 1.000 \\
\hline 24 & $1.25 \mathrm{E}-04$ & $1.25 \mathrm{E}-04$ & 1.000 \\
\hline 28 & $7.010 \mathrm{E}-05$ & $7.020 \mathrm{E}-05$ & 1.001 \\
\hline 32 & $3.930 \mathrm{E}-05$ & $3.940 \mathrm{E}-05$ & 1.002 \\
\hline 36 & $2.210 \mathrm{E}-05$ & $2.210 \mathrm{E}-05$ & 1.000 \\
\hline 40 & $1.240 \mathrm{E}-05$ & $1.240 \mathrm{E}-05$ & 1.000 \\
\hline 44 & $6.900 \mathrm{E}-06$ & $6.900 \mathrm{E}-06$ & 1.000 \\
\hline 48 & $3.900 \mathrm{E}-06$ & $3.900 \mathrm{E}-06$ & 1.000 \\
\hline
\end{tabular}




\section{APPENDIX B}

Athyroid patient \#1, $100 \mathrm{mCi}$

$\begin{array}{lllll}\mathrm{q}(1) & 0 & 0 & .99997 & 3.088 \mathrm{E}-05 \\ \mathrm{q}(2) & 0 & 0 & -3.797 \mathrm{E}-04 & 3.797 \mathrm{E}-04 \\ \mathrm{q}(3) & 1.505 \mathrm{E}-03 & 0 & -1.505 \mathrm{E}-03 & -6.179 \mathrm{E}-07 \\ \mathrm{q}(4) & 0 & .99849 & -.99808 & -4.099 \mathrm{E}-04\end{array}$

$\mathrm{q} 1(\mathrm{t})=0 * \exp (-0) * \mathrm{t}+0 * \exp (-0) * \mathrm{t}+0.99997 * \exp -(1.99+0.086) * \mathrm{t}+3.09 \mathrm{E}-05 * \exp$ $-(0.15+0.086)^{*} \mathrm{t}$

$q 1(t)=0.99997 * \exp -(1.99+0.086) * t+3.09 \mathrm{E}-05 * \exp -(0.15+0.086) * t$

$\mathrm{r} 1=0.99997 /(1.99+0.086)+3.09 \mathrm{E}-05 /(0.15+0.086)=0.482$ days

0.482 days $* 24 \mathrm{hrs} / 1$ day $=11.6$ hours

$\mathrm{q} 2(\mathrm{t})=0 * \exp (-0) * \mathrm{t}+0 * \exp (-0) * \mathrm{t}-3.80 \mathrm{E}-04 * \exp -(1.99+0.086) * \mathrm{t}+3.80 \mathrm{E}-04 * \exp -$ $(0.15+086) * t$

$\mathrm{q} 2(\mathrm{t})=-3.80 \mathrm{E}-04 * \exp -(1.99+0.086)^{*} \mathrm{t}+3.80 \mathrm{E}-04 * \exp -(0.15+0.086)^{*} \mathrm{t}$

$\mathrm{r} 2=-3.80 \mathrm{E}-04 /(1.99+0.086)+3.80 \mathrm{E}-04 /(0.15+0.086)=1.43 \mathrm{E}-03$ days $1.43 \mathrm{E}-03$ days $* 24 \mathrm{hrs} / 1$ day $=0.034$ hours

$\mathrm{q} 3(\mathrm{t})=0.00151^{*} \exp -(0+0.086)^{*} \mathrm{t}+0^{*} \exp (-0 \mathrm{t})-0.00151^{*} \exp -(1.99+0.086)^{*} \mathrm{t}-$ $6.18 \mathrm{E}-07 * \exp -(0.15+0.086) * \mathrm{t}$

$q 3(t)=0.00151 * \exp -(0.086)^{*} t-0.00151 * \exp (-1.99+0.086)^{*} t-6.18 \mathrm{E}-07 * \exp$ $-(0.15+0.086)^{*} \mathrm{t}$

$\mathrm{r} 3=0.00151 / 0.086-0.00151 /(1.99+0.086)-6.18 \mathrm{E}-07 /(0.15+0.086)=1.68 \mathrm{E}-02$ days $1.68 \mathrm{E}-02$ days $* 24 \mathrm{hrs} / 1$ day $=0.404$ hours

$\mathrm{WB}$ residence time $=12.04$ hours 
Athyroid patient \#2, $150 \mathrm{mCi}$ dose

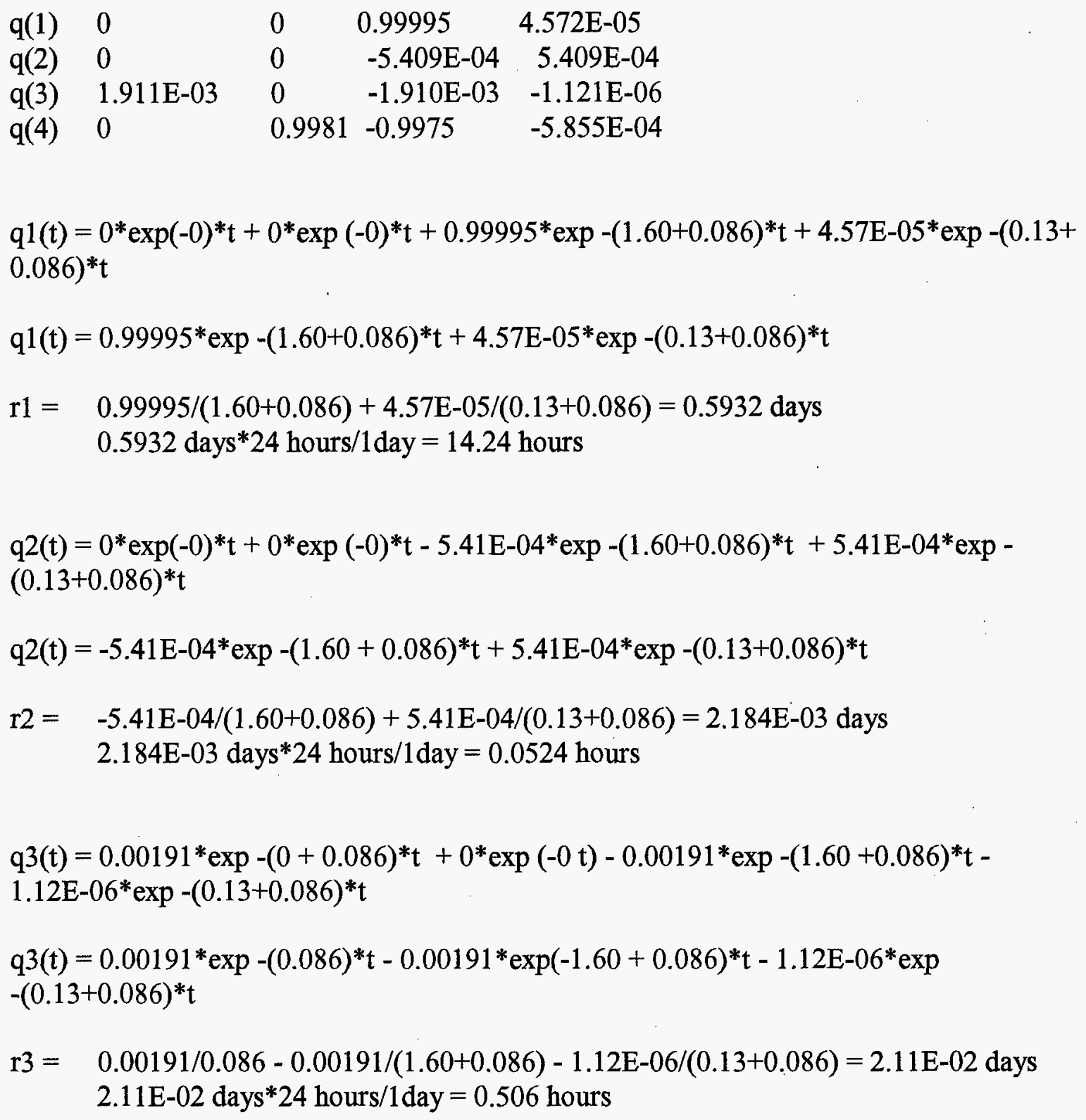

WB residence time $=14.80$ hours 
Athyroid patient \#3 $4 \mathrm{mCi}$

$\begin{array}{lllll}\mathrm{q}(1) & 0 & 0 & 0.99992 & 7.559 \mathrm{E}-05 \\ \mathrm{q}(2) & 0 & 0 & -8.694 \mathrm{E}-04 & 8.694 \mathrm{E}-04 \\ \mathrm{q}(3) & 1.7523 \mathrm{E}-03 & 0 & -1.751 \mathrm{E}-03 & -1.656 \mathrm{E}-06 \\ \mathrm{q}(4) & 0 & 1.00 & -0.99985 & -9.458 \mathrm{E}-04\end{array}$

$\mathrm{q} 1(\mathrm{t})=0 * \exp (-0) * \mathrm{t}+0 * \exp (-0)^{*} \mathrm{t}+0.99992 * \exp -(1.75+0.086)^{*} \mathrm{t}+7.56 \mathrm{E}-05^{*} \exp$ $-(0.14+0.086)^{*} \mathrm{t}$

$\mathrm{q} 1(\mathrm{t})=0.99992 * \exp -(1.75+0.086) * \mathrm{t}+7.56 \mathrm{E}-05^{*} \exp -(0.14+0.086)^{*} \mathrm{t}$

$\mathrm{r} 1=0.99992 /(1.75+0.086)+7.56 \mathrm{E}-05 /(0.14+0.086)=0.5449$ days 0.5449 days $* 24 \mathrm{hrs} / 1$ day $=13.1$ hours

$\mathrm{q} 2(\mathrm{t})=0 * \exp (-0) * \mathrm{t}+0 * \exp (-0) * \mathrm{t}-8.69 \mathrm{E}-04 * \exp -(1.75+0.086) * \mathrm{t}+8.69 \mathrm{E}-04 * \exp -$ $(0.14+086)^{*} \mathrm{t}$

$q 2(t)=-8.69 E-04 * \exp -(1.75+0.086) * t+8.69 E-04 * \exp -(0.14+0.086)^{*} t$

$\mathrm{r} 2=-8.69 \mathrm{E}-04 /(1.75+0.086)+8.69 \mathrm{E}-04 /(0.14+0.086)=3.37 \mathrm{E}-03$ days $3.37 \mathrm{E}-03$ days $* 24 \mathrm{hrs} / 1$ day $=0.081$ hours

$\mathrm{q} 3(\mathrm{t})=0.00175^{*} \exp -(0+0.086)^{*} \mathrm{t}+0^{*} \exp (-0 \mathrm{t})-0.00175^{*} \exp -(1.75+0.086)^{*} \mathrm{t}-$ $1.66 \mathrm{E}-06 * \exp -(0.14+0.086) * \mathrm{t}$

$q 3(t)=0.00175 * \exp -(0.086) * t-0.00175 * \exp (-1.75+0.086) * t-1.66 \mathrm{E}-06 * \exp$ $-(0.14+0.086)^{*} \mathrm{t}$

$\mathrm{r} 3=0.00175 / 0.086-0.00175 /(1.75+0.086)-1.66 \mathrm{E}-06 /(0.14+0.086)=1.939 \mathrm{E}-02$ days $1.939 \mathrm{E}-02$ days $* 24 \mathrm{hrs} / 1$ day $=0.465$ hours

WB residence time $=13.65$ hours 
M97053797

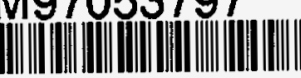

Report Number (14) DOE/OR/00033- T765

Publ. Date (11) $\quad 199707$

$\begin{array}{ll}\text { Sponsor Code (18) } & \text { DOE/EH, XF } \\ \text { UC Category (19) } & U C-600, D O E / E R\end{array}$

DOE 